\title{
COMPORTAMENTO GEOQUÍMICO DOS ELEMENTOS TERRAS RARAS NOS ALTERITOS DA JAZIDA DE FOSFATO E TITÂNIO DE TAPIRA (MINAS GERAIS, BRASIL): A IMPORTÂNCIA DOS FOSFATOS
}

\author{
FRANCOIS SOUBIÈS*, ADOLPHO J. MELFI** e F. AUTEFAGE***
}

\begin{abstract}
GEOCHEMICAL BEHAVIOUR OF RARE EARTH ELEMENTS IN ALTERITES OF PHOSPHATE AND TITANIUM ORE DEPOSITS IN TAPIRA (MINAS GERAIS, BRAZIL): THE IMPORTANCE OF THE PHOSPHATES. The geochemical behaviour of the rare earth elements (REE) during the supergenic evolution of the rocks is not yet well known. This paper deals with the REE behaviour in ferralitic alteration profiles of the residual phosphate and titanium deposit of Tapira, originated from pyroxenites and peridotites containing apatite and perovskite. This study was carried out on a rock constituted essentially of apatite, perovskite and titaniferous magnetite, with diopside and phlogopite as accessory minerals. The analysis of a microfractured and silicified fresh rock has shown perovskite as the main bearing REE primary mineral (1.5 to $2.0 \% \mathrm{RE}_{2} \mathrm{O}_{3}$ ). The alteration of this rock occuring on a first stage with preservation of the volume (isovolume) leads to: 1. total removal of silica (opal and quartz); 2 . partial dissolution of primary apatite along the fractures and neoformation of secondary apatite, enriched in fluor and depleted in REE; and 3. total transformation (pseudomorphose) of perovskite into microbothroidal anatase in the voids of which a crystal association (geodes) of rare earth and Ca phosphate of rhabdophane group is neoformed. On a second alteration stage it is observed that: $\mathbf{1}$. all the apatite is dissolved leaving behind important assembly of voids; 2 . the phosphate of the rhabdophane group is partially dissolved and replaced by a phosphate of the crandallite group rich in REE; 3. a certain Ti mobilization occurs in the interior of the anatase (corrosion gulf; titaneous cutans) followed by its partial epigenization by ferruginous products and an initial alteration of the titaniferous magnetite. The study seems to indicate that in Tapira: 1 . the phosphorous has a fundamental role on trapping the REE released by hydrolysis of the bearing primary minerals; 2 . the REE remain in the alterites and are fixed in mineralogical phases of a sequence of REE phosphates richer in aluminium; 3. the REE and the Ti remain closely associated in the studied weathering phases.
\end{abstract}

Keywords: Phosphate, earth-rare elements, titanium, weathering.

RESUMO O comportamento geoquímico dos elementos terras raras (ETR) durante a evolução supérgena das rochas não se encontra ainda perfeitamente definido. Neste trabalho, procurou-se, por meio da utilização de técnicas de microscopia óptica, microscopia eletrônica de varredura e microssonda eletrônica, caracterizar o comportamento geoquímico desses elementos nos perfis de alteração ferralítica da jazida residual de fosfato e titânio de Tapira, cuja gênese está ligada à evolução superficial de piroxenitos e peridotitos ricos em apatita e perovskita. $\mathrm{O}$ estudo foi realizado sobre uma fácies litológica constituída essencialmente de apatita, perovskita e magnetita titanífera, com diopsídio e flogopita como minerais acessórios. A análise da rocha original inalterada, microfraturada e silicificada, permitiu caracterizar a perovskita como o principal mineral primário portador de ETR $(1,5$ a $2,0 \%$ $\left.\mathrm{TR}_{2} \mathrm{O}_{3}\right)$, e a apatita com importância secundária $\left(0,1\right.$ a $\left.0,4 \% \mathrm{TR}_{2} \mathrm{O}_{3}\right)$. A alteração desta rocha, que em um primeiro estágio se verifica com visível preservação de volume (isovolume), provoca: 1. eliminação total da silica (opala e quartzo); 2. dissolução parcial da apatita primária, acompanhando as fraturas, e neoformação de apatita secundária, enriquecida de flúor e empobrecida em ETR; 3. transformação total (pseudomorfose) da perovskita em anatásio microbotrioidal, nos vazios dos quais se desenvolvem associações de cristais (geodos) de um fosfato de ETR e $\mathrm{Ca}$, do grupo do rabdofânio. Em um estágio posterior de alteração, verifica-se que: 1. toda a apatita é dissolvida, deixando importantes vazios no conjunto; 2 o fosfato do grupo do rabdofânio é parcialmente dissolvido e substituído por um fosfato do grupo da crandallita e rico em ETR; 3. ocorre uma certa mobilização do titânio do anatásio (golfos de corrosão, cutanas titaniferas), assim como a epigenização parcial destes por produtos ferruginosos, além de um início de alteração da magnetita titanífera. Os estudos parecem mostrar que em Tapira: 1. o fósforo tem um papel fundamental na captura dos ETR liberados por hidrólise dos minerais primários; 2. os ETR se mantêm nos alteritos e se fixam em fases minerais que caracterizam uma seqüência de fosfates de ETR cada vez mais aluminosos; 3. os ETR e o Ti permanecem, nos estádios de alteração estudados, intimamente associados.

Palavras-chaves: Fostato, titânio, elementos terras raras, intemperismo.

INTRODUÇÃO A jazida residual de fosfato e titânio de Tapira, localizada $35 \mathrm{~km}$ a sudeste de Araxá, no oeste do Estado de Minas Gerais, ocupa a borda norte de um complexo ultramáfico-alcalino carbonatítico, de idade cretácea superior $(70 \mathrm{Ma})$, de forma aproximadamente circular $(6 \mathrm{~km}$ de diâmetro) e intrusivo em uma série metamórfica pré-cambriana (quartzitos e xistos do Grupo Canastra). A noroeste de Tapira e por uma distância de cerca de $300 \mathrm{~km}$, outros complexos intrusivos análogos (Araxá, Salitre, Serra Negra, Catalão etc.) encontram-se alinhados na borda da Bacia do Paraná, formando a "Província alcalino-carbonatítica cretácica do Alto Paranaíba" (DNPM 1984, CBMM 1984) (Fig. 1).
A gênese dessa jazida é o resultado direto de um enriquecimento supérgeno a partir de rochas ultramáficas, anormalmente ricas em titânio e fósforo (Grossi Sad \& Torres 1971, Cruz \& Cheney 1976, Lindenmayer 1978, Vaz de Melo 1983). São essencialmente piroxenitos (diopsídio, diopsídio-augita ou egirina-augita) e peridotitos (forsterita), com estrutura orientada e granulação geralmente grossa. Além desses minerais essenciais, essas rochas possuem em média $10 \%$ de perovskita e outro tanto de apatita, que são acompanhadas, subordinadamente, por ilmenita, magnetita titanífera, flogopita ou biotita e melanita. Veios de carbonatito (sövito) cortam irregularmente este conjunto intrusivo.

\footnotetext{
* ORSTOM, UR/IG Laboratoire de Minéralogie, Université Paul Sabatier 39, Alices Jules Guesde, 31000, Toulouse, France

** Instituto Astronômico e Geofísico, Universidade de São Paulo, Caixa Postal 30627, CEP 01051, São Paulo, SP, Brasil

*** INSA, Dept. Génie Civil, Avenue de Rangueil, 31077 Toulouse CEDEX, France
} 


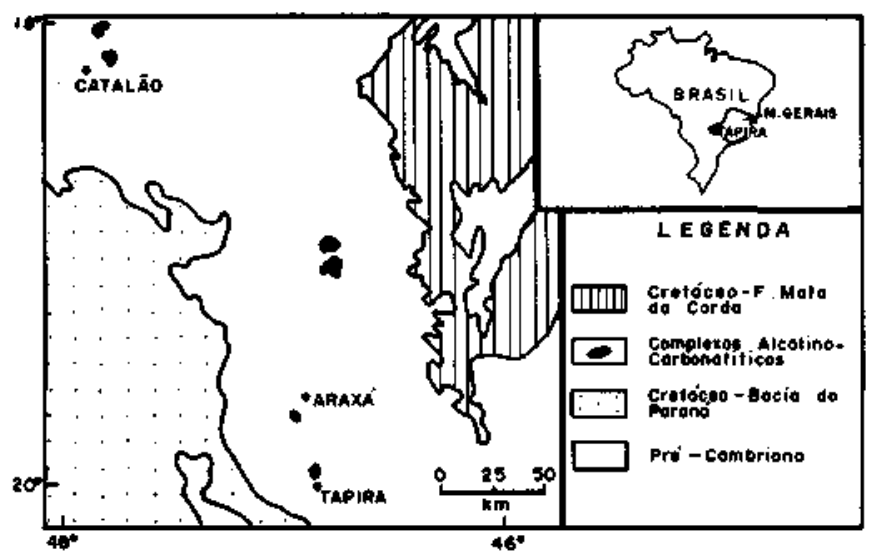

Figura 1 - Mapa geológico esquemático e de localização da Jazida de Tapira

Figure 1 - Geological sketch map and location of Tapira Mine

Durante o Terciário e o Quaternário, uma longa evolução lateritizante, e uma erosão mecânica, provavelmente limitada, conduziram à formação de uma importante cobertura de alteração (em média $90 \mathrm{~m}$ de espessura, podendo, entretanto, atingir até $200 \mathrm{~m}$ ), onde se concentram elementos com baixa mobilidade sob condições hidrolíticas (Ti, Nb, ETR, Fe, Al, $P$ etc.). Dessa forma, foi gerada uma jazida laterítica de primeira importância, cujas reservas estimadas são da ordem de $743.10^{6}$ t de minério fosfático, com $8,3 \%$ de $\mathrm{P}_{2} \mathrm{O}_{5}$ e de 191. $10^{6}$ t de minério titanífero, com $21 \% \mathrm{de}^{\mathrm{TiO}_{2}}$.

Os trabalhos realizados na área pelas companhias mineiras (DNPM 1984, CBMM 1984) mostram que, de uma forma esquemática, a partir das rochas frescas até os latossolos de superfície, ocorre: transformação progressiva da perovskita em anatásio, que é o constituinte essencial do minério de titânio; dissolução da apatita, progressivamente substituída por fosfates secundários aluminosos do grupo da crandallita; transformação parcial da magnetita em oxi-hidróxido de ferro; vermiculitização, seguida de caolinização da biotita; e eliminação completa do piroxênio e da olivina.

Entretanto, existem dúvidas sobre a natureza exata das fases neoformadas nos alteritos e sobre a dinâmica dos elementos que aí aparecem concentrados. Estudos pormenorizados, conduzidos em jazidas análogas (Valarelli 1971, Carvalho 1974, Baecker 1983, para a jazida de Catalão - GO, e Costa 1987, Lemos \& Costa 1987, para a jazida de Maicuru - PA), apesar de sensíveis a tais preocupações, não fornecem os elementos necessários para a precisa caracterização das paragêneses secundárias, e o modo de transferência, no interior do perfil de alteração, de certos elementos (Ti, Nb, ETR etc.), altamente concentrados nas jazidas residuais. Este é, em particular, o caso dos ETR objeto essencial do presente estudo.

Os ETR aparecem em quantidades apreciáveis nos minérios titano-fosfatados de Tapira onde seus teores variam de $0,2 \% \mathrm{TR}_{2} \mathrm{O}_{3}$ na rocha-mãe, até $0,6 \% \mathrm{TR}_{2} \mathrm{O}_{3}$ nos horizontes de superfície, o que corresponde a um enriquecimento da ordem de $55 \%$ (alteração isovolume). O caráter residual dos ETR no curso da alteração meteórica manifesta-se aqui, da mesma forma que em vários outros locais (Bonnot-Courtois 1981, Humphris 1984, Fleet 1984). Entretanto, as fontes portadoras não foram ainda perfeitamente identificadas, em particular nos alteritos. Por meio de estudos mineralógicos e geoquímicos, pretende-se definir para os ETR, não somente as fases portadoras, mas também a maneira como estas fases se associam no espaço e no tempo, enquanto ocorre a progressão das frentes de alteração nos materiais originais.

AMOSTRAGEM E MÉTODOS DE ESTUDO Os trabalhos de exploração da jazida a céu aberto e as inúmeras sondagens existentes em Tapira mostram que o depósito titano-fosfático é nitidamente zonado (Vaz de Melo 1983). Esta zonação parece resultar de diferenças nas velocidades de alteração dos minerais originais e de variações na litologia inicial. Do topo para a base do depósito, observam-se sucessivamente (Fig. 2):

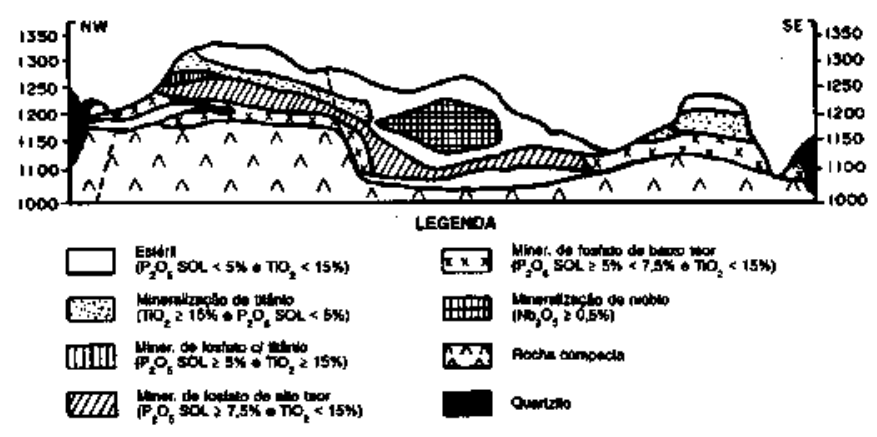

Figura 2 - Perfil típico das zonas mineralizadas da Jazida de Tapira. Zonas estudadas: mineralização de titânio (zona 2), mineralização de fosfato e titânio (zona 3) e mineralização de fosfato (zona 4)

Figure 2 - Typical profile of mineralized zones of Tapira Mine. Studied levels: titanium mineralization (zone 2), phosphate and titanium mineralization (zone 3 ), phosphate mineralization (zone 4)

- Uma zona latossólica (zona 1) com estruturas pedológicas, de aproximadamente $20 \mathrm{~m}$ de espessura, onde a fração fina argilosa é dominante. Esta zona é constituída, predominantemente, por caolinita, gibbsita, goethita, hematita, fosfates secundários aluminosos e anatásio, além de magnetita e quartzo residuais. Um nível concrecionário, por vezes cimentado formando uma carapaça, pode estar presente em profundidade. Esta zona é considerada, economicamente, como "estéril" $\left(\mathrm{P}_{2} \mathrm{O}_{5}\right.$ solúvel $<5 \%$ e $\left.\mathrm{TiO}_{2}<15 \%\right)$;

- Uma zona rica em titânio (zona 2) de aproximadamente 40 m de espessura, onde as estruturas da rocha original são parcialmente conservadas. A composição mineralógica é sensivelmente a mesma encontrada nos latossolos acima; porém, com anatásio amarelado bem mais abundante e fração fina mais restrita. As micas, nesta zona, aparecem transformadas em vermiculita e um pouco de perovskita é ainda visível. Os teores de $\mathrm{TiO}_{2}$ ultrapassam $15 \%$, enquanto os de $\mathrm{P}_{2} \mathrm{O}_{5}$ solúvel permanecem abaixo de $5 \%$;

- Uma zona rica em titânio e fosfato (zona 3) onde as estruturas da rocha original são bem preservadas. Nesta zona, aparecem grandes quantidades de apatita primária, parcialmente dissolvida, acompanhada de perovskita, quase completamente transformada em anatásio esverdeado, de micas, em grande parte vermiculitizadas, e de magnetita titanífera, parcialmente transformada em maghemita ou hematita. Esta zona, de aproximadamente $15 \mathrm{~m}$ de espessura, não é uniformemente presente na frente de lavra, porém constitui o minério mais importante, com $\mathrm{TiO}_{2}$ superior a $15 \%$ e $\mathrm{P}_{2} \mathrm{O}_{5}$ solúvel superior a $5 \%$.

- Uma zona rica em fosfato (zona 4), com cerca de $80 \mathrm{~m}$ de espessura e que se prolonga para a base até as rochas frescas. É constituída por piroxenitos e peridotitos menos transformados pela alteração meteórica. A perovskita é fresca, assim como a apatita que se torna dominante; magnetita titanífera, diopsídio, olivina ferruginizada, micas, mais ou menos alteradas, e granada são minerais subsidiários. Os teores em $\mathrm{P}_{2} \mathrm{O}_{5}$ solúvel podem variar de menos de $5 \%$ (estéril) a mais de $7,5 \%$ (minério rico), enquanto os de $\mathrm{TiO}_{2}$ estão sempre abaixo de $15 \%$. Setores silicificados aparecem freqüentemente nesta zona e a presença de veios de carbonatito são intensificados nas proximidades da rocha fresca. 
As amostras estudadas foram coletadas nas zonas 2, 3 e 4, onde a alteração é grosseiramente isovolume, e correspondem a diferentes estágios de evolução de uma rocha de granulação grossa, quase exclusivamente constituída de apatita e perovskita. Apesar de outras fácies litológicas, mais ricas em silicates e de texturas variadas, terem sido coletadas, os estudos foram intencionalmente concentrados sobre esse material pelo fato de oferecer, ao mesmo tempo, forte concentração em minerais portadores potenciais de elementos terras raras e cristais de grande tamanho que facilitam o acompanhamento passo a passo das evoluções mineralógicas.

As amostras, após impregnação com resinas sintéticas, foram estudadas ao microscópio óptico. Este estudo foi complementado por análises por difratometria de raios $\mathrm{X}$ e análises térmicas diferencial e ponderai sobre fases separadas por microamostragem e análises químicas qualitativas (microscópio eletrônico de varredura equipado com EDS) e quantitativas (microssonda eletrônica).

As análises por microssonda foram obtidas em equipamento CAMECA, tipo Camebax SX50, automática e equipada de espectrômetro WDS, pertencente ao Laboratório de Mineralogia da Universidade Paul Sabatier e INSA, Toulouse, França. Os padrões utilizados para as sondagens de ETR foram: monazita de Madagascar e diferentes vidros sintéticos à base de óxidos de ETR, e as medidas foram obtidas utilizando-se tensão de aceleração $\mathrm{E}=15 \mathrm{kV}$ e uma corrente $\mathrm{I}=20 \mathrm{~mA}$.

Evidentemente, a microssonda (WDS) não é o equipamento melhor adaptado para a dosagem de ETR, sobretudo quando estes se apresentam em fracas concentrações, o que é geralmente o caso. Se, por um lado, sua utilização apresenta a vantagem de evitar separações de fases, normalmente impossíveis de serem realizadas nos alteritos, devido ao tamanho dos cristais neoformados e do íntimo estado de agregação dos minerais, por outro, a existência de interferências entre as raias $\mathrm{X}$ dos ETR faz com que seja difícil detectar teores inferiores a 200 ppm para qualquer um desses elementos (Roeder 1985, Mitchell \& Reed 1988). Sobre a raia $L \alpha_{1}$, que é a mais intensa, somente $\mathrm{La}, \mathrm{Ce}, \mathrm{Nd}, \mathrm{Sm}, \mathrm{Tb}, \mathrm{Dy}$ e $\mathrm{Yb}$ podem ser dosados sem correções e sobre a raia $\mathrm{L} \beta_{1}$ menos intensa, somente $\mathrm{Ce}, \mathrm{Pr}, \mathrm{Nd}, \mathrm{Sm}$ e Dy. Em todos os outros casos, correções mais ou menos importantes devem ser introduzidas nos resultados obtidos (Roeder 1985). Outro inconveniente é a existência de interferências de certos elementos no domínio das raias L $\alpha, \beta, \gamma$ dos ETR. As mais prejudiciais, no caso do material de Tapira são: $\mathrm{K} \alpha \mathrm{Ti} \leftrightarrow \mathrm{L} \alpha \mathrm{Ba}, \mathrm{K} \beta \mathrm{Ti} \leftrightarrow \mathrm{L} \alpha \mathrm{Ce}, \mathrm{L} \beta \mathrm{Ba}$ $\leftrightarrow \mathrm{L} \alpha \mathrm{Ce}, \mathrm{L} \beta \mathrm{Ce} \leftrightarrow \mathrm{K} \alpha \mathrm{Zr}$. Entretanto, este problema pode ser contornado com a escolha judiciosa de raias de dosagem e utilização de fatores de correção.

Finalmente, na ausência de uma gama completa de padrões perfeitamente adaptados e também de programas de correções específicos, somente $\mathrm{La}$, Ce e $\mathrm{Nd}$ puderam ser dosados nos minerais com uma boa precisão. Entretanto, este fato não é demasiadamente prejudicial, pois sabe-se que para as rochas ígneas a somatória dos teores de $\mathrm{La}, \mathrm{Ce}$ e Nd representa, em média, mais de $70 \%$ do total em ETR (Hermann 1969) e que esta percentagem é ainda mais elevada nas rochas magmáticas máficas ou ultramáficas-alcalinas, muito enriquecidas em ETR leves (Hermann 1969, Cullers \& Graf 1984). No que concerne às fases neoformadas portadoras de ETR que, como se sabe, podem apresentar valores bem elevados nesses elementos, controles semiquantitativos foram, sistematicamente, efetuados e mostraram que, neste caso também, La, Ce, Nd, Pr constituem o essencial do estoque em ETR. É evidente que eventuais fenômenos de fracionamento, ligados à lixiviação diferencial de certos ETR, como tem sido assinalado por vários autores (Duddy 1980, Bonnot-Courtois 1981, Sígolo et al. 1987, Fortin 1989, Banfield \& Eggleton 1989), não puderam ser detectados, a não ser quando afetam os próprios elementos dosados.
COMPORTAMENTO DOS ETR NA FÁCIES INICIAL DE ALTERAÇÃO (ZONA 4 - RICA EM FOSFATO) Análise petrográfica e mineralógica Macroscopicamente, a rocha de aspecto brechóide e sem orientação bem definida apresenta-se semicompacta e muito densa $(d=3,35)$, formada por cristais milimétricos a centimétricos de perovskita cinza escuro, subautomorfos ou automorfos (octaedros) e de magnetita cinza-preta, os quais estão imersos em uma mesostase de apatita verde escura, finamente granulada (Foto 1).

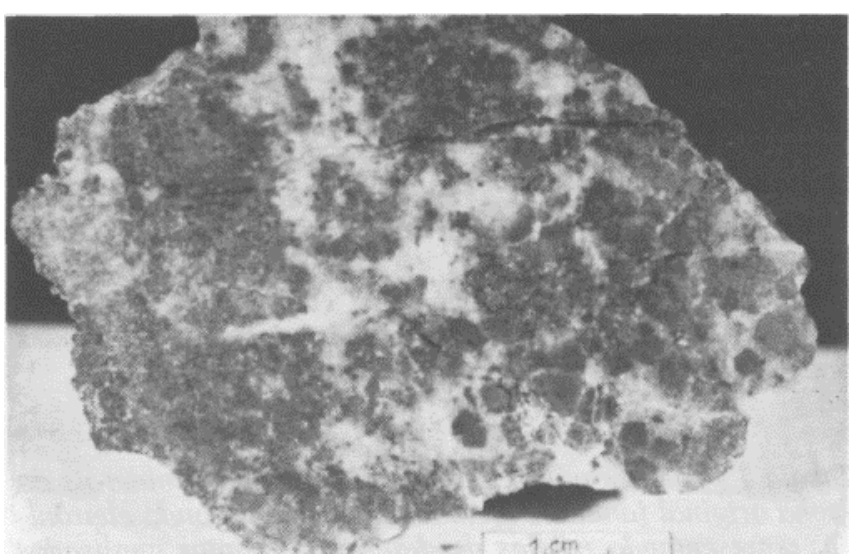

Foto 1 - Fácies inicial de alteração. Rocha rica em perovskita e magnetita (zonas escuras) e apatita (zonas claras), recortadas por vênulas preenchidas por material silicoso

Photo 1 - Early stage of alteration. Parental material constituted by perovskite and magnetite (dark minerals) and apatite (white mineral), cross cutting veins of silica minerals

A perovskita é o mineral dominante e forma, juntamente com a magnetita, de 60 a $70 \%$ do volume total da rocha. Inúmeras vênulas silicosas, acinzentadas ou esbranquiçadas, milimétricas a submilimétricas ocupam as fraturas, por vezes abertas, que recortam a rocha em todos os sentidos.

Ao microscópio, a microfraturação intensa da rocha aparece claramente (Foto 2). As vênulas de opala e quartzo recortam a rocha e/ou englobam cristais de perovskita, magnetita e apatita. A rocha foi, visivelmente, submetida a uma fraturação hidráulica sob forte pressão, que provocou simultaneamente a disjunção dos cristais constituintes, porém sem

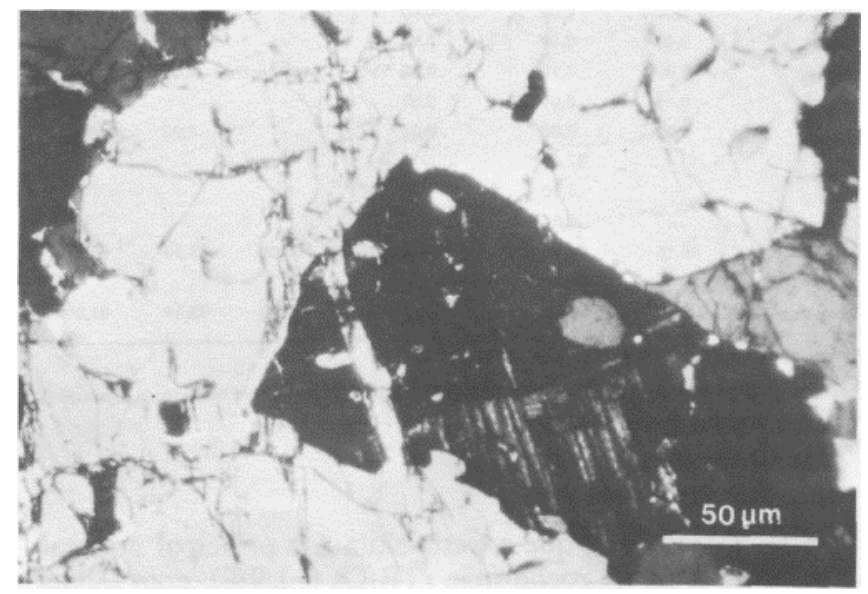

Foto 2 - Fotomicrogrqfia mostrando rede de fraturas silicificadas que corta perovskita e apatita primárias (Nicóis X) Photo 2 - Primary perovskite and apatite cutted by silicified fractures. (Nicols X) 
grandes deslocamentos, e o preenchimento das fraturas por silica, sem ocorrência de notáveis fenômenos de dissolução. Esta silificação não é, aparentemente, um fenômeno meteórico, fato aliás, já descrito em outros locais (Heinrich 1980), mas provavelmente contemporânea à colocação dos corpos carbonatíticos no maciço.

A apatita é bastante fresca, mas rica em inclusões fluidas. A perovskita é geralmente sã, mas pode, esporadicamente, apresentar manchas escuras ou amarronzadas, cuja análise na microssonda mostrou tratar-se de zonas com ligeiras perdas de $\mathrm{Ca}$, que podem corresponder a provável início de alteração meteórica, que promove desorganização do retículo cristalino. Diopsídio e flogopita, frescos ou pouco alterados, aparecem como pequenos cristais intersticiais ou como microinclusões na perovskita, juntamente com freqüentes inclusões de apatita e magnetita. A magnetita é rica em titânio e a ilmenita, rara, aparece como grãos bem individualizados disseminados em cristais de magnetita.

Análises químicas Os resultados das análises obtidas por microssonda estão apresentados na tabela 1 .

Tabela 1 - Análise química das principais fases minerais da rocha original (análises efetuadas por microssonda eletrônica, representando médias de dezenas de pontos analisados em diversos cristais)

Table 1 - Microprobe compositions of minerals constituing the parental rock of Tapira Mine

\begin{tabular}{|c|c|c|c|c|c|c|}
\hline & $\begin{array}{c}\text { Perorskitt } \\
x\end{array}$ & $\begin{array}{c}\text { Apatita } \\
*\end{array}$ & $\begin{array}{c}\text { Matemala allieotos } \\
\text { nus rlaturas } \\
*\end{array}$ & $\begin{array}{c}\text { Mappetita } \\
x\end{array}$ & $\begin{array}{c}\text { Diopsldio } \\
\%\end{array}$ & $\begin{array}{c}\text { Flopopite } \\
\mathbf{x}\end{array}$ \\
\hline $\mathrm{Naz} O$ & 0.16 & 0,12 & 0,03 & + & 0,30 & 0.09 \\
\hline $\mathrm{k}_{\mathrm{q}} \mathrm{O}$ & 0,00 & • & 0,01 & - & 0,01 & 1,56 \\
\hline 600 & 37.67 & $51,7 \mathrm{~B}$ & 0,00 & 0,03 & 23,42 & 1.25 \\
\hline MgO & 0,00 & 0,01 & 0,06 & 0,03 & 14,29 & 18,09 \\
\hline $0 \times 0$ & $1,80^{\circ}$ & 0,03 & 0,00 & · & 0,01 & 0,00 \\
\hline 500 & 0,46 & 0,91 & 0,00 & $\cdot$ & 0,00 & 0,00 \\
\hline $\mathbf{s \omega}_{2}$ & 0,42 & 0,69 & 90,85 & 0,15 & 49.24 & 35,68 \\
\hline $\mathrm{AllO}_{2}$ & 0.06 & 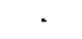 & 0,00 & 0,16 & 0,60 & 10.42 \\
\hline FeO & . & 0,09 & 0,00 & - & 4,32 & 0.50 \\
\hline $\mathrm{F}_{\mathbf{s}_{2}} \mathrm{Ola}_{\mathrm{a}}$ & 1,07 & $\cdot$ & - & 91,41 & - & - \\
\hline $\mathrm{To}_{2}$ & 52,51 & - & 0,07 & 6,15 & 0,00 & 1.70 \\
\hline $\ln _{2} \mathrm{O}_{5}$ & 0.49 & - & + & 0,07 & $\cdot$ & - \\
\hline $2 \mathrm{NO}_{2}$ & 0,01 & - & 0,00 & 0,00 & - & - \\
\hline$n 0$ & 0,00 & 0,02 & 0,00 & 0,25 & 0,11 & 0,17 \\
\hline $\mathrm{Cr}_{2} \mathrm{O}_{3}$ & • & - & - & 0,11 & 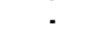 & - \\
\hline Nio & - & - & . & 0,07 & - & - \\
\hline $\mathrm{w}_{2} \mathrm{O}_{5}$ & • & - & - & 0,8 & $=$ & $=$ \\
\hline $\mathrm{wo}_{3}$ & 0,00 & 0,00 & 0,00 & - & $=*$ & + \\
\hline $\mathrm{ThO}_{2}$ & 0,00 & 0,00 & 0,00 & - & + & - \\
\hline $\mathrm{LugO}_{3}$ & 0,49 & 0,11 & 0,00 & * & - & - \\
\hline $\mathrm{Cow}_{2} \mathrm{O}_{3}$ & $0,95^{\circ}$ & 0,12 & 0,00 & = & 0,00 & 0.00 \\
\hline $\mathrm{H}_{2} \mathrm{O}_{3}$ & 0,46 & 0,01 & 0,00 & * & - & - \\
\hline $\mathrm{r}_{2} \mathrm{O}_{3}$ & 0,02 & 0,02 & 0,01 & + & 0,06 & 0,00 \\
\hline$P_{2} O_{5}$ & $\cdot$ & 37,60 & + & * & - & - \\
\hline F & - & 3,10 & $=$ & $=$ & . & $=$ \\
\hline 0 & - & 0,01 & . & $=$ & - & - \\
\hline Total & $\$ 6,15$ & an, & 91,13 & 100,00 & 99,56 & 81,60 \\
\hline $0=\mathrm{F}$ & & 1,31 & & & & \\
\hline Totel cortighos & 96.15 & 93,65 & $D 1,13$ & 100,00 & 93,59 & 81,60 \\
\hline
\end{tabular}

Vê-se, claramente, que a perovskita é o principal mineral portador de ETR na rocha mãe $\left(\mathrm{TR}_{2} \mathrm{O}_{3}=1,9 \%\right)$, com teores bem superiores aos da apatita $(0,24 \%)$ e a dos veios silicosos $(0,06 \%)$. Os outros minerais, praticamente, não intervém na retenção de ETR, fato este previsível, tendo em vista os pequenos valores dos coeficientes de partição sólido-magma que os caracterizam (Henderson 1984). Portanto, existe em Tapira, desde o início da alteração supérgena, uma forte associação titânio - ETR, a qual, como será visto adiante, será mantida nos estádios posteriores de evolução.

Os estudos químicos permitiram certas considerações sobre a cristaloquímica desses diferentes minerais:

Perovskita A baixa taxa de substituição em $\mathrm{Na}$ e $\mathrm{Nb}$ afasta a perovskita de Tapira daquelas encontradas nos carbonatitos ou nos nefelina sienitos (lueshita, latrappita ou loparita) (Nickel \& Adam 1963, Vlasov 1966, Heinrich 1980). Porém, ao contrário, a aproxima da perovskita dos kimberlitos (Dawson 1980, Mitchell 1986, Mitchell \& Reed 1988). A formula estrutural $\mathrm{XYO}_{3}$, calculada sobre base de três ions oxigênio e com o ferro como $\mathrm{Fe}^{3+}$ (Muir et al. 1984), será assim representada:

\section{[ Ca0,963 $\left.\mathrm{Na}_{0,009} \mathrm{Sr}_{0,006} \mathrm{Ce}_{0,009} \mathrm{La}_{0,006} \mathrm{Nd}_{0,003}\right]_{\mathbf{0}, 996}$}

\section{$\left[\mathbf{T i}_{0,941} \mathbf{F e}_{0,020} \mathbf{N b}_{0,006} \mathbf{A I}_{0,003}\right] \Sigma_{0,970} \mathbf{O}_{3}$}

A fórmula permite observar que o sítio $X$ está completamente prenchido $(\Sigma \sim 1)$, mas que o sítio Y apresenta um ligeiro déficit em cations. A hipótese mais plausível é que outros cations, de tamanho pequeno e não dosados $(\mathrm{Cr}, \mathrm{V}$ etc.), devam integrar o retículo. Entretanto, é também possível que certas posições estejam vagas, como já foi assinalado para certos cristais de perovskita (Vlasov 1966), nos quais o equilíbrio de carga é assegurado por substituições de certos íons oxigênio por agrupamentos $\mathrm{OH}$.

Apatita Todas as análises efetuadas na microssonda não completaram $100 \%$. O déficit encontrado pode, em parte, resultar da abundância de inclusões fluidas existentes nos cristais de apatita. Entretanto, é mais provável que certos elementos não analisados sejam a causa eventual desse déficit. Um cálculo sobre a base $5(\mathrm{Ca}+\mathrm{Na}+\mathrm{Sr})$ indica a existência de 2,9 (P + Si) em lugar de 3 para a malha do mineral. Como o enxofre não foi detectado na análise qualitativa, pode-se então pensar que substituições $\left(\mathrm{CO}_{3} \mathrm{OH}\right) \rightarrow\left(\mathrm{PO}_{4}\right)$ tenham afetado o retículo. Esta hipótese já foi sugerida por Vaz de Melo (1983), com base em análises químicas por via úmida realizadas sobre a mesma apatita de Tapira. As análises mostram que existe mesmo um déficit $(\mathrm{F}+\mathrm{Cl})$; com efeito, uma flúor-apatita estequiométrica deveria conter $\mathrm{F}=3,7 \%$, enquanto a apatita estudada apresenta apenas 3,1\%. Como os teores em $\mathrm{Cl}$ são baixos, é provável que $(\mathrm{OH})$ integre a estrutura desse mineral. Este tipo de substituição $(\mathrm{OH} \rightarrow(\mathrm{F}, \mathrm{Cl}))$ é aliás, clássica para a apatita (Deer et al 1962, Nash 1984). Portanto, apesar de $\mathrm{CO}_{2}$ e $\mathrm{H}_{2} \mathrm{O}$ não terem sido dosados, é provável que a apatita da rocha-mãe seja uma "flúor-hidroxilcarbonato apatita". Convém assinalar que estas análises estão de acordo com outras, em particular no tocante aos teores em ETR, obtidos em microssonda por Roeder et al (1987).

Materiais silicosos de preenchimento de fraturas A análise química, associada ao aspecto provocado pelos impactos à microssonda, mostra, nitidamente, que estas fraturas são preenchidas por produtos voláteis ricos em silica. Trata-se, portanto, de opala.

Magnetita Mesmo na rocha fresca, a magnetita titanífera apresenta-se parcialmente alterada. $\mathrm{O}$ cálculo de fórmula estrutural, realizado a partir da análise de alguns cristais de magnetita, sugere que o ferro encontra-se totalmente oxidado. Trata-se, portanto, de maghemita titanífera (Deer et al. 1962), como parece confirmar o exame sob luz refletida.

Diopsídio e flogopita Os minerais analisados não se encontram totalmente frescos, o que, em parte, explica o déficit 
encontrado nas análises. O cálculo dos cations mostra que o piroxênio se situa próximo do pólo diopsidio (diopsídio: $85 \%$, hedenbergita: $15 \%$ ) e que a mica, com uma relação $\mathrm{Mg} / \mathrm{Fe}=$ 3,4 é uma flogopita.

COMPORTAMENTO DOS ETR NA FÁCIES INTERMEDIÁRIA (ZONA 3 - RICA EM TITÂNIO E FOSFATO) Análise petrográfica e mineralógica Macroscopicamente, a rocha apresenta sensivelmente a mesma textura brechóide que a precedente (Foto 2). Entretanto, é menos densa, muito mais friável e de coloração mais clara. Numerosos octaedros justapostos, cinza-esverdeados, de anatásio, apresentam tamanhos de alguns milímetros até $1 \mathrm{~cm}$. Associam-se a concentrações irregulares de magnetita, cinza-escura, e ambos encontram-se imersos em uma massa esverdeada e finamente granulada de apatita (40 a $50 \%$ da rocha). Esta massa é recortada em todos os sentidos por numerosos filonetes esbranquiçados, de 0,1 a alguns milímetros de largura, que contornam freqüentemente os grãos de anatásio. Uma importante microporosidade, formada por vazios entre grãos isolados e microgeodos recobertos por pequenos prismas hexagonais esbranquiçados, ocorre associada.

Microscopicamente, constata-se que estes filonetes se organizam como as micro e macrofraturas encontradas na rocha original. Seu conteúdo silicoso foi, entretanto, completamente eliminado e depósitos de apatita secundária preenchem parcialmente os vazios formados (Vaz de Melo 1983). Esta apatita apresenta, freqüentemente, estrutura microfibrosa, com fibras orientadas perpendicularmente às paredes dos vazios. Nas fraturas mais desenvolvidas, elas se organizam em camadas fibrosas sucessivas ao redor de grãos irregulares, comumente corroídos em forma de rendas, de apatita primária; neste caso, apresenta-se como cristais zonados, com hábito hexagonal, formando microgeodos (Foto 3). Esta apatita não é encontrada nas fraturas que atravessam os cristais de anatásio ou de magnetita-maghemita.

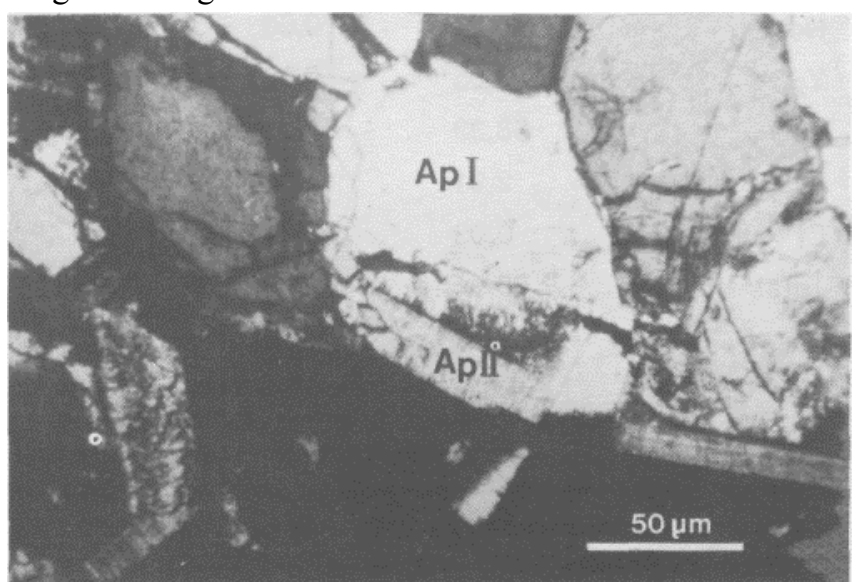

Foto 3 - Fotomicrografia de apatita secundária (ApII), formada sobre apatita primária (Apl) parcialmente dissolvida. (Nicóis X)

Photo 3 - Secondary apatite (ApII) substituting the original apatite (Apl) which is partially dissolved. (Nicols X)

Com base no modo de distribuição, na forma, na organização interna, nas inclusões de octaedros, assim como na natureza de seu constituinte essencial, o exame do anatásio, efetuado em diferentes escalas de observação, revela que este é produto da alteração in situ da perovskita. Essas pseudomorfoses são comumente isoladas da matriz apatítica circunvizinha e apresentam sempre uma microporosidade bem elevada (Foto 4). Sua organização interna, visível somente em cortes ultra-finos, é caracterizada pela justaposição de células $\left(10\right.$ a $\left.10^{2} \mu \mathrm{m}\right)$, cujas paredes são formadas de granules ou bastonetes imbricados, de 5 a $10 \mu \mathrm{m}$, castanho-amarelados em LN e amarelos em LP, enquanto a parte central, muito vacuolar (aspecto rendado), apresenta preenchimento mais homogêneo e opaco (LN: cinza-amarronzado escuro e LP: vermelho-escuro). $\mathrm{O}$ conjunto dessas células forma uma rede mais ou menos ortogonal, cujos vazios (intracelulares e fraturas que atravessam todo o cristal) são freqüentemente recobertos por minúsculos cristais aciculares de alguns um de largura e de aproximadamente $10 \mu \mathrm{m}$ de comprimento, de coloração amarelo-esverdeada em LN, e branco-acinzentada em LP, com extinção reta (Foto 5). Trata-se de um fosfato de ETR que será definido mais adiante. Algumas inclusões de apatita ou magnetita frescas, são, por vezes, visíveis no interior de anatásio.

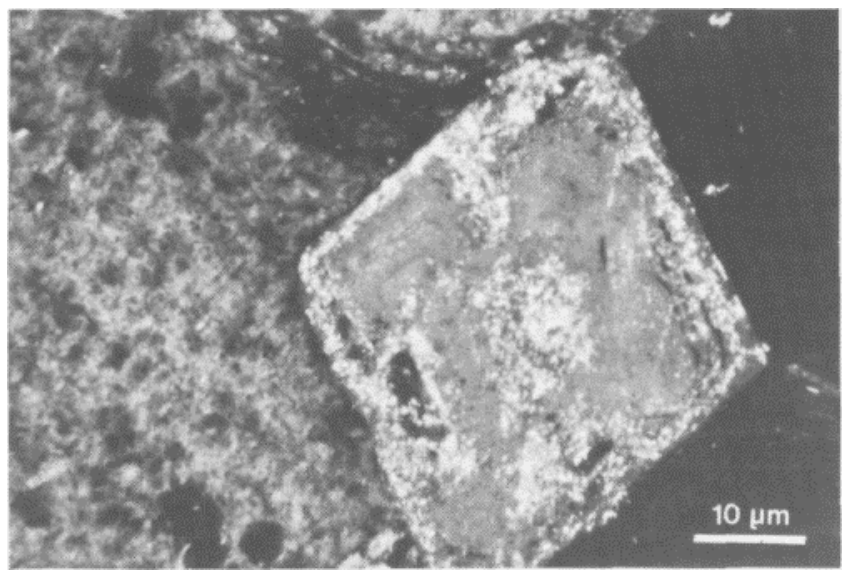

Foto 4 - Fotomicrografia de anatásio pseudomórfico sobre perovskita. (Nicóis X)

Photo 4 - Pseudomorphosis of anatase on perovskite. (Nicols X)

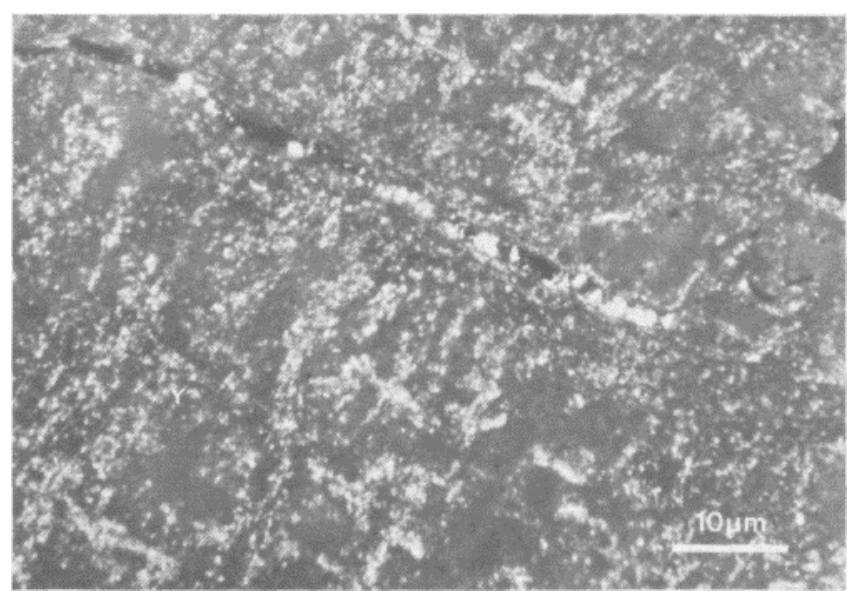

Foto 5 - Fotomicrografia mostrando cristal de anatásio com fratura preenchida por fosfato do grupo do rabdofânio. É bem visível a textura "celular malhada"do anatásio. (Nicóis X)

Photo 5 - Anatase with vein fractures filled by phosphate of rhabdophane group. Note the typical orthogonal texture of anatase. (Nicols X)

A magnetita, por sua vez, é ainda fresca e pode conter inclusões de diopsídio ou flogopita. Estes minerais apresentam-se bastante frescos, ao contrário do que acontece comumente na rocha, onde ocorrem totalmente alterados: produtos ferruginosos para o diopsídio e argilominerais (vermiculita ou caolinita) para a flogopita. Raras inclusões de perovskita inalterada são, por vezes, observadas no interior de apatita primária não fraturada.

Os estudos microscópicos revelam, portanto, uma transformação bem avançada da rocha, porém ainda incompleta 
e sensivelmente isovolume. Esta transformação, sem dúvida ligada à circulação de fluidos nas fraturas e contatos dos grãos, caracteriza-se por saídas importantes de matéria (eliminação de silica nas fraturas, dissolução parcial da apatita, dissolução incongruente de perovskita), por certas neoformações (apatita secundária, anatásio, fosfato de ETR) e pela conservação parcial da paragênese original (apatita primária, magnetita titanífera).

Análise química das fases neoformadas Apatita secundária As análises, por microssonda, de apatita primária e secundária foram reunidas na tabela 2 . A apatita primária não se diferencia muito daquela encontrada na rocha fresca, em particular pelos valores em ETR $\left(\sum \mathrm{TR}_{2} \mathrm{O}_{3} \cong 0,2 \%\right)$. A apatita neoformada, ao contrário, aparece empobrecida em $\operatorname{ETR}\left(\left(\sum \mathrm{TR}_{2} \mathrm{O}_{3} \cong 0,1 \%\right)\right.$, Si e $\mathrm{Sr}$ e muito enriquecida em flúor. $\mathrm{O}$ cálculo da fórmula estrutural mostra que o flúor, e em menor quantidade o cálcio, excedem largamente os valores normais. Pela fórmula $\mathrm{Ca}_{10}\left(\mathrm{PO}_{4}\right)_{6}(\mathrm{~F}, \mathrm{Cl}, \mathrm{OH})_{2}$, o cálculo dos cations e do flúor com base em $26(\mathrm{O}, \mathrm{F}, \mathrm{Cl}, \mathrm{OH})$ fornece os valores: $\mathrm{Ca}=10,834, \mathrm{P}=6,037 \mathrm{e} \mathrm{F}=3,099$. Exceto por eventuais erros analíticos, a razão destes excedentes pode ser explicada pela presença de fluorita, precipitada entre as fibras de apatita e não detectada nos estudos microscópicos. É possível também, mas pouco provável, que o flúor participe mais fortemente da carcaça aniônica do mineral $(\mathrm{F} \rightarrow \mathrm{O})$. Finalmente, pode-se notar que, estando o $\mathrm{P}$ muito próximo do valor teórico, parece pouco provável que esta apatita seja carbonatada, ao contrário da apatita primária.

Anatásio Ao microscópio eletrônico de varredura, os fragmentos de cristais de anatásio examinados com pequeno aumento exibem uma massa desorganizada, de aspecto escoriáceo, vacuolar, sem nenhuma orientação ou repetição de elementos estruturais (Foto 6). Com forte aumento, certos tipos de organização podem aparecer localmente: massas colunares, onde pequenas colunas se alinham paralelamente entre si; massas botrioidais, com textura fibrosa; redes ortogonais de elementos discoidais (Fotos 7 e 8). O tipo de organização que, globalmente, pode ser qualificado de coloforme é sintomático do crescimento simultâneo, em solução, de numerosos microgermes esferulíticos (Grigor'ev 1965).

Todas as regiões analisadas, qualquer que seja a organização, mostram sempre, sensivelmente, a mesma composição química, cujo valor médio é apresentado na tabela 2 . Em relação à perovskita original, vê-se que somente subsistem. $\mathrm{Ti}$, Fe e $\mathrm{Nb}$, tendo sido completamente eliminados os elementos alcalinos, alcalinos terrosos e ETR. Parte do Si, Al e P fica aprisionada na estrutura do anatásio. O fato de as análises não completarem 100\% deve estar relacionado à existência de urna porosidade ultrafina na organização dos cristalitos, a qual é por vezes visível ao MEV com forte aumento. É possível ainda que $(\mathrm{OH})$ integre o retículo cristalino do anatásio, ficando então uma parte do titânio sob a forma de $\mathrm{Ti}^{3+}$ no lugar do $\mathrm{Ti}^{4+}$.

Fosfato do grupo do rabdofânio No sistema poral do anatásio coloforme, que resulta sobretudo da perda de matéria por ocasião da alteração de perovskita, mas também da dissolução de inclusões e da dessilicificação das microfraturas, é que se cristaliza um fosfato de ETR que as análises químicas permitem associar ao grupo do rabdofânio $\left(\mathrm{XZO}_{4}\right.$. 1-2 $\left.\mathrm{H}_{2} \mathrm{O}\right)$. Os cristais, que ocupam em média 5\% do anatásio, apresentam-se, quando examinados ao MEV, como prismas hexagonais, bem formados e comumente arranjados em "feixes" (Fotos 9 e 10); seu diminuto tamanho dificulta a análise por microssonda. Porém, estudos em diferentes regiões de várias seções delgadas permitiram a obtenção de resultados razoáveis que permitiram sua caracterização.
Tabela 2 - Análises químicas (microssonda eletrônica) de minerais encontrados na zona 3 (fácies intermediária de alteração). Os resultados representam valores médios de dezenas de medidas pontuais

Table 2 - Microprobe analises of minerals from zone 3 of Tapira Mine

\begin{tabular}{|c|c|c|c|}
\hline & $\begin{array}{c}\text { Apatita } \\
\text { primária } \\
\%\end{array}$ & $\begin{array}{c}\text { Apatita } \\
\text { secundária } \\
\%\end{array}$ & $\begin{array}{c}\text { Anatásio } \\
\%\end{array}$ \\
\hline $\mathrm{Na}_{2} \mathrm{O}$ & 0,13 & 0,03 & - \\
\hline $\mathrm{CaO}$ & 53,15 & 54,57 & 0,28 \\
\hline $\mathrm{MgO}$ & 0,03 & 0,04 & - \\
\hline $\mathrm{BaO}$ & 0,03 & 0,01 & 0,00 \\
\hline Sro & 0,88 & 0,06 & 0,00 \\
\hline $\mathrm{SiO}_{2}$ & 0,55 & 0,03 & 0,41 \\
\hline $\mathrm{Al}_{2} \mathrm{O}_{3}$ & - & $\cdot$ & 0,78 \\
\hline FeO & 0,02 & 0,02 & - \\
\hline $\mathrm{Fe}_{2} \mathrm{O}_{3}$ & - & - & 2,77 \\
\hline $\mathrm{TiO}_{2}$ & - & - & 87,71 \\
\hline $\mathrm{Nb}_{2} \mathrm{O}_{5}$ & - & - & 0,67 \\
\hline MnO & 0,00 & 0,00 & - \\
\hline $\mathrm{UO}_{3}$ & 0,00 & 0,00 & - \\
\hline $\mathrm{ThO}_{2}$ & 0,02 & 0,00 & - \\
\hline $\mathrm{La}_{2} \mathrm{O}_{3}$ & 0,07 & 0,02 & 0,00 \\
\hline $\mathrm{Ce}_{2} \mathrm{O}_{3}$ & 0,09 & 0,01 & 0,00 \\
\hline $\mathrm{Nd}_{2} \mathrm{O}_{3}$ & 0,04 & 0,06 & 0,00 \\
\hline $\mathrm{Y}_{2} \mathrm{O}_{3}$ & 0,05 & 0,02 & 0,00 \\
\hline $\mathrm{P}_{2} \mathrm{O}_{5}$ & 38,33 & 38,66 & 1,26 \\
\hline $\mathrm{F}$ & 2,91 & 6,01 & $=$ \\
\hline $\mathrm{Cl}$ & 0,03 & 0,01 & - \\
\hline Total & 96,31 & 99,55 & 93,88 \\
\hline$O=F$ & 1,23 & 2,53 & \\
\hline $\mathrm{O}=\mathrm{Cl}$ & 0,01 & & \\
\hline Total corrigido & 95,07 & 97,02 & 93,88 \\
\hline
\end{tabular}

O padrão de difração de raios $\mathrm{X}$ do fosfato do grupo do rabdofânio de Tapira apresenta boa concordância com a dos outros minerais do grupo, obtidos por diferentes autores (Tab. 3).

Estas espécies minerais, assim como o rabdofânio, são produtos da alteração hidrotermal de certos pegmatites graníticos ou sieníticos, ou ainda encontrados em certas jazidas uraníferas. Apresentam-se comumente, da mesma forma que o mineral de Tapira, em agregados fibrorradiais de pequenos cristais aciculares que formam as cavidades. Sawka et al (1986) e Benfield \& Eggleton (1989) também assinalaram o rabdofânio como produto de alteração meteórica de apatita em granitos, e Meintzer \& Mitchell (1988), na alteração de allanita.

As análises reunidas na tabela 4 permitiram discriminar entre estas diversas espécies. Todos os elementos suscetíveis de integrarem o retículo desses minerais foram detectados 


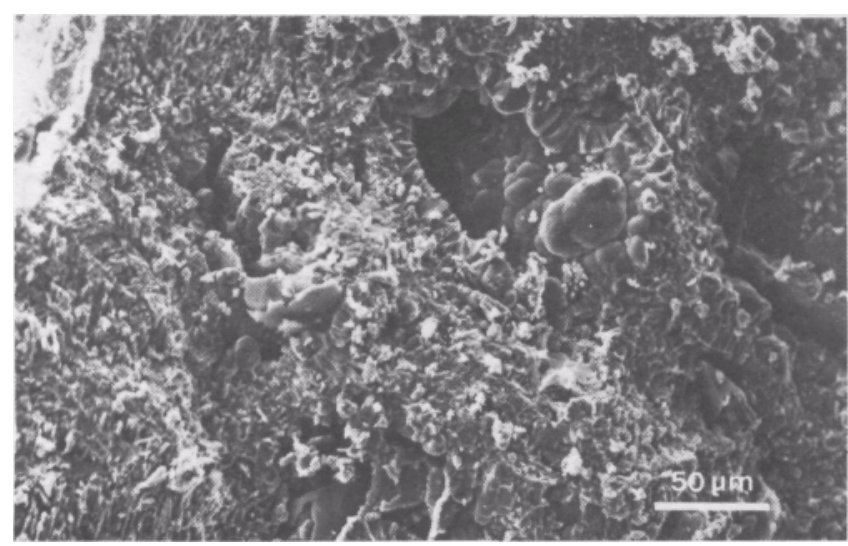

Foto 6 -Aspecto escoriáceo, vacuolar e microbotrioidal mostrado pelo anatásio (micrografia ao M. E. V.)

Photo 6 - S.E.M. photomicrograph. Anatase crystals showing spongy, visicular and microbothryoidal textures

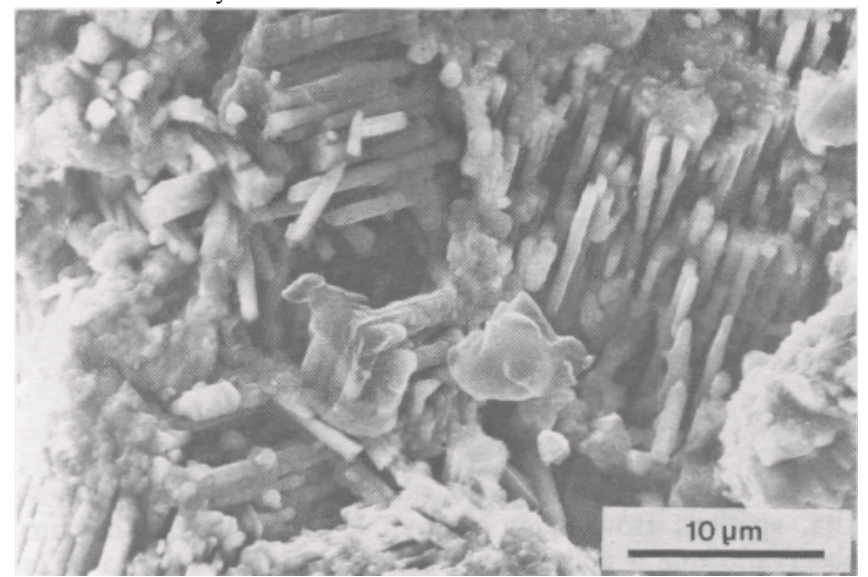

Foto 7 - Organização interna do anatásio. Pequenas colunas justapostas visíveis ao M.E.V.

Photo 7 - Prismatic texture of anatase at S.E.M.

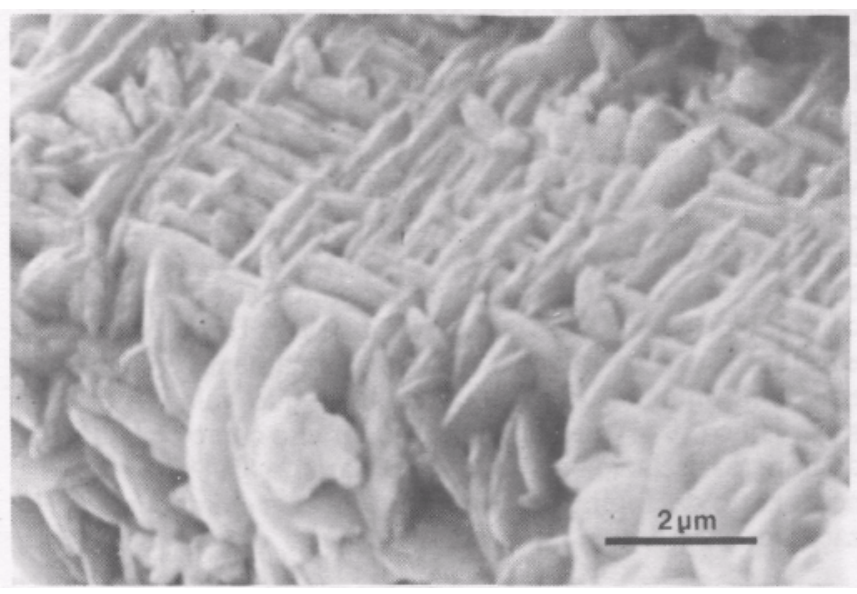

Foto 8 - Organização interna do anatásio. Rede ortogonal constituída por formas discóides (M.E.V.)

Photo 8 - Orthogonal net-work texture formed by discoidal anatase crystals (S.E.M.)

qualitativamente, com exceção de $\mathrm{Pb}$ e $\mathrm{S}$. Um microteste com $\mathrm{HC} 1$ diluído não revelou a presença de carbonato. $\mathrm{O}$ déficit observado nas análises parece, a primeira vista, ligado à existência de água zeolítica no mineral; os estudos termoponderais de misturas rabdofânio-anatásio parecem confirmar a presença de água, pois ocorrem perdas importantes ao redor de $160^{\circ} \mathrm{C}$ e mais fracas por volta de $370^{\circ} \mathrm{C}$. Evidentemente, não se pode excluir a possibilidade desse déficit estar, pelo menos em parte,

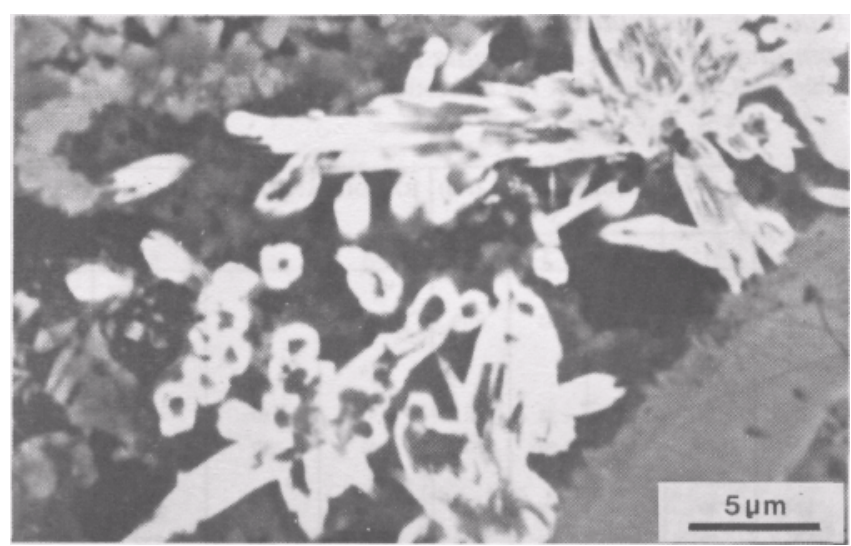

Foto 9 - Fotomicrografia obtida em M.E.V. (elétrons retrodifundidos) mostrando cristais de fosfato do grupo do rabdofânio formados no sistema poral do anatásio e apresentando início de epigenia por um fosfato do grupo da crandallita

Photo 9 - S.E.M. back-scattering image of phosphate of the rhabdophane group filling cavities the anatase porosity. Note that the phosphate of rhabdophane group is partially substituted by one phosphate of crandallite group

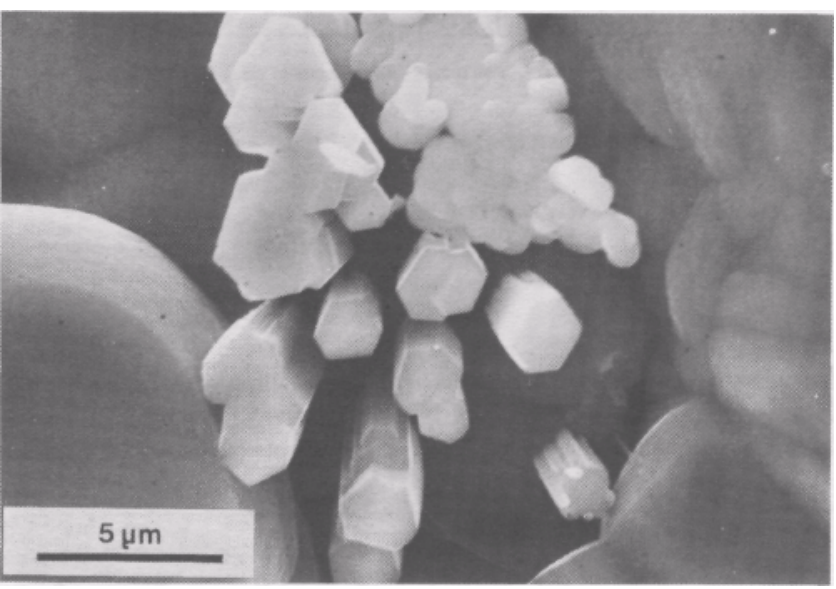

Foto 10 - Detalhe da foto 6 (M.E.V.), onde aparece nitidamente a morfologia prismática hexagonal dos cristais de fosfato do grupo do rabdofânio

Photo 10 - Prismatic hexagonal morphology of crystals of phosphate of the rhabdophane group (detail of Photo 6, S.E.M.)

ligado à presença de poros que devem existir entre os pacotes dos cristais aciculares analisados. Qualquer que seja o caso, é possível calcular as fórmulas estruturais e confirmar a coerência das análises. Não levando-se em conta as pequenas quantidades de Ti, $\mathrm{Si}, \mathrm{Al}$ e Fe detectadas, mas, certamente, ligadas ao anatásio, que serve de suporte para o fosfato do grupo do rabdofânio, e o Ba, superestimado devido a interferência do Ti na raia $L \alpha$, constata-se que as proporções catiônicas calculadas sobre base de quatro íons oxigênio (Tab. 5) estão de acordo com uma fórmula estrutural do tipo $\left(\mathrm{M}^{\mathrm{x}+}\right) \mathrm{PO}_{4} \cdot \mathrm{nH}_{2} \mathrm{O}$, que é aquela dos minerais do grupo do rabdofânio. Um cálculo com base em 1P revela, entretanto, um déficit de cargas cationnicas. Devido a existência de perdas de água fortemente retida, evidenciadas pelas análises termoponderais ao redor de $370^{\circ} \mathrm{C}$, pode-se supor que este déficit é compensado pela presença de $(\mathrm{OH})$ que entra na estrutura para diminuir a carga aniônica, como mostrado por Nriagu \& Moore (1984) e Burt (1989) para estes tipos de minerais: $\mathrm{Ca}^{2+}(\mathrm{OH}) \rightarrow \mathrm{TR}^{3+} \mathrm{O}$. A fórmula estrutural média do mineral de Tapira pode então ser escrita:

$\left(\mathrm{Ca}_{0,38} \mathrm{Ce}_{0,26} \mathrm{La}_{0,21} \mathrm{Nd}_{0,10}, \ldots\right)\left(\left[\mathrm{PO}_{3,62}(\mathrm{OH})_{0,38}\right]\right) \cdot \mathrm{xH}_{2} \mathrm{O}(\mathrm{x} \sim 1)$ 
Tabela 3 - Comparação entre o espectro de difração de raios X (pó) do fosfato do grupo do rabdofânio de Tapira (misturado com anatásio) e as raias mais intensas de diferentes espécies deste grupo

Table 3 - Comparison of X-ray diffraction spectrum of the Tapira phosphate of rhabdophane group and those of other minerals belonging to the same group

\begin{tabular}{|c|c|c|c|c|c|c|c|c|c|c|c|c|c|c|c|c|c|}
\hline \multicolumn{2}{|c|}{ TAPIRA } & \multicolumn{3}{|c|}{$\begin{array}{c}\text { RABDOFANIO-(NA) } \\
\text { (1) }\end{array}$} & \multicolumn{2}{|c|}{$\begin{array}{c}\text { RABDOFANIO-(Ce) } \\
\text { (2) }\end{array}$} & \multicolumn{2}{|c|}{$\begin{array}{c}\text { RABDOFANIO-(د) } \\
\text { (3) }\end{array}$} & \multicolumn{2}{|c|}{$\begin{array}{c}\text { BROCKITA } \\
\text { (A) }\end{array}$} & \multicolumn{2}{|c|}{$\begin{array}{c}\text { TRISTRAMITA } \\
\text { (5) } \\
\end{array}$} & \multicolumn{3}{|c|}{$\begin{array}{c}\text { NIMGYofTA } \\
\text { (6) }\end{array}$} & \multicolumn{2}{|c|}{$\underset{\text { (In }}{\text { GRAYITA }}$} \\
\hline$d A$ & 1 & $d h$ & I & thil & $\Delta \lambda$. & 1 & $d A$ & 1 & $d A$ & $I$ & dA & 1 & $\alpha$ & 1 & nEl & $d \boldsymbol{\alpha}$ & $I$ \\
\hline 6.02 & so & 6.03 & 35 & 1010 & 609 & 90 & 6,07 & 60 & 6.06 & 40 & 5,96 & 40 & $\begin{array}{l}6,35 \\
5,90 \\
5,05\end{array}$ & $\begin{array}{l}20 \\
40 \\
20\end{array}$ & $\begin{array}{l}001 \\
020 \\
011\end{array}$ & 6.05 & 40 \\
\hline 4,36 & 30 & 4,38 & 55 & roil & 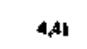 & 0 & 4,40 & 80 & 4.37 & 70 & 4.37 & 4 & 4,33 & 6 & 11 & 4,35 & 60 \\
\hline (XO)AN & (352k) & 3,48 & 50 & 1120 & 3.51 & 70 & 3,69 & 60 & 3,47 & 50 & 3.46 & 30 & $\begin{array}{l}3,45 \\
3,38\end{array}$ & $\begin{array}{l}20 \\
60\end{array}$ & $\begin{array}{l}130 \\
200\end{array}$ & 3,46 & 20 \\
\hline 3,04 & 4 & {$[3,03\}$} & (3) & (1131) & (na) & - & (na) & - & (no.) & - & $\{3,04\}$ & (2) & (3.19) & (6) & $(002)$ & (na) & - \\
\hline 3,01 & 90 & 3.01 & 90 & 2080 & $3,0 t$ & 100 & 3.02 & 100 & 3,03 & 100 & 299 & 100 & 3,02 & 100 & $\left.\begin{array}{c}040 \\
(022)\end{array}\right)$ & 3,03 & 100 \\
\hline 2,82 & 100 & 2,02 & 100 & $10 \mathrm{i} 2$ & 2,83 & 90 & 2,13 & 10 & 2,83 & $x 0$ & 2,83 & 100 & 21 & $\omega$ & $\left\{\begin{array}{l}1,2 \\
\}\end{array}\right.$ & 282 & $\mathbf{8 0}$ \\
\hline (X) AN & $\left\{\begin{array}{l}(231 \lambda) \\
(233 \lambda)\end{array}\right\}$ & 2.35 & 20 & 112ิ2 & 2.36 & 40 & 2.36 & $\omega$ & 2.37 & 30 & 2.35 & 25 & 2.34 & $\omega$ & 132 & 2,36 & 20 \\
\hline $2: 14$ & 30 & 2,15 & so & 2151 & 2.16 & $\boldsymbol{6}$ & 2,15 & 0 & 2.15 & $\pi$ & 2,14 & 30 & 2.13 & $\mathbf{s}$ & 241 & 2.15 & 80 \\
\hline OOAN & (1,89h) & 1.916 & 13 & sobs & 1.927 & 40 & 1,92 & 40 & 1.99 & 30 & 1.906 & 20 & 1903 & 20 & 331 & 1.914 & 20 \\
\hline 1,251 & so & 1.853 & so & $\begin{array}{c}2132 \\
2210\end{array}$ & 1,863 & 60 & 1059 & 60 & 1.16 & 50 & 1.250 & so & $1 . \$ 45$ & 40 & 242 & 1,856 & 60 \\
\hline 1.740 & 30 & $t, 74$ & 20 & \}$\left._{20,03}^{26+10}\right\}$ & 1,749 & 10 & 1,743 & 20 & 1.75 & 30 & 1.740 & 10 & 1.740 & $\infty$ & 043 & 1,748 & 20 \\
\hline$(000)+N$ & $(1.20 \mathrm{~h})$ & 1,600 & 20 & 3032 & 1.710 & 40 & 1,704 & 20 & 1,60 & $\omega$ & 1006 & 25 & 1.92 & 40 & 400 & 1,704 & 20 \\
\hline ox)서 & $(0.67 \mathrm{~A})$ & 1,67 & 15 & 310 & 2,684 & 40 & 1075 & 200. & 1.63 & 3 & 1,662 & 11 & 1, & 20 & 332 & 1,606 & 20 \\
\hline
\end{tabular}

$(\mathrm{X}),(\mathrm{XX})$ - Interferências parcial $(\mathrm{X})$ ou total $(\mathrm{XX})$ com certas raias do anatásio.

(n.o.) - raia não observada.

(1) - Atkin et al. 1983; Bowles \& Morgan 1984.

(2) - Walenta 1979.

(3) - Muto et al. 1959; Walenta 1959; PDF 12-277.

Tabela 4 - Análises químicas (microssonda eletrônica) do fosfato do grupo do rabdofânio de Tapira

Table 4 - Microprobe analises of the Tapira phosphate of rhabdophane group

\begin{tabular}{|c|c|c|c|c|c|c|c|}
\hline \multirow{2}{*}{ Oxidhs } & \multicolumn{7}{|c|}{ Porcentisgem poto dos oxidos } \\
\hline & $\%$ & * & $x^{2}$ & $*$ & $\%$ & $\%$ & \% \\
\hline $\mathrm{CaO}$ & 8,00 & 7,81 & 8,28 & 8,65 & 10,11 & 9,61 & 11,26 \\
\hline BaO & 0,23 & 0,39 & 0,67 & 0,46 & 0,63 & 0,61 & 0,32 \\
\hline Sno & 0,34 & 0,26 & 0,35 & 0,33 & 0,19 & 0,57 & 0,06 \\
\hline $\mathrm{SiO}_{2}$ & 0,21 & 0,16 & 0,27 & 0,12 & 0,20 & 0,16 & $0,2 i$ \\
\hline $\mathrm{Al}_{2} \mathrm{O}_{3}$ & 0,14 & 0.18 & 0,17 & 0,10 & 0,13 & 0,18 & 0,09 \\
\hline $\mathrm{F}_{82} \mathrm{O}_{3}$ & 0,00 & 0,07 & 0,87 & 0,00 & 0,00 & 0,01 & 0,00 \\
\hline $\mathrm{TH}_{2}$ & 1,96 & 2,57 & 1,76 & 0,78 & 1,88 & 1,92 & 2,66 \\
\hline $\mathrm{ZrO}_{2}$ & 0,00 & - & - & 0,00 & - & 0,00 & - \\
\hline $\mathrm{NO}_{3}$ & 0,00 & - & - & 0,00 & - & 0,00 & - \\
\hline $\mathrm{ThO}_{2}$ & 0,35 & - & - & 0,00 & - & 0,04 & - \\
\hline $\mathrm{L}_{2} \mathrm{O}_{3}$ & 18.77 & 18,43 & 15,80 & 11,87 & 13,54 & 12,57 & 8,65 \\
\hline $\mathrm{Ce}_{2} \mathrm{O}_{3}$ & 12,81 & 14,62 & 16,69 & 17,28 & 19,63 & 20,06 & 24,62 \\
\hline $\mathrm{No}_{2} \mathrm{O}_{3}$ & 4,93 & 6.57 & 7,05 & 6,85 & B,40 & 8,17 & 10,55 \\
\hline $\mathrm{r}_{2} \mathrm{O}_{3}$ & 0,84 & 0,46 & 0.57 & 0,62 & 0,55 & 0,85 & 0,52 \\
\hline $\mathrm{P}_{2} \mathrm{O}_{5}$ & 29,77 & 30,20 & 29,29 & 26,22 & 31,64 & 29,96 & 32,79 \\
\hline Total & 78,43 & a1, 73 & 81,77 & 75,28 & 66,80 & 84,80 & 81,73 \\
\hline
\end{tabular}

A riqueza em cálcio, cation dominante na posição $\mathrm{M}^{\mathrm{x}+}$, diferencia nitidamente este mineral do rabdofânio-(Ce), do rabdofânio-(La) e do rabdofânio-(Nd); por outro lado, a ausência quase total de U e Th e a riqueza em ETR diferencia-no, igualmente, de outras espécies do grupo do rabdofânio contendo cálcio. Trata-se, pois, muito provavelmente, de uma nova espécie mineral, que está atualmente sendo melhor caracterizada. Nota-se que este mineral reflete de forma mar-
(4) - Fisher \& Meyrowitz 1962; PDF 15-248.

(5) - Atkin et al. 1983.

(6) - Muto et al. 1959; PDF 12-273.

(7) - Dooly\& Hathaway 1961.

cante o ambiente de formação, rico em ETR e cálcio (perovskita, apatita); Bowlen \& Morgan (1984), aliás, já haviam observado que a composição catiônica do rabdofânio pode variar fortemente em função do ambiente de formação. Observa-se, igualmente, que, de um conjunto de cristais para outro, as proporções entre os diferentes ETR presentes no retículo podem variar. Um certo fracionamento, que ainda necessita ser melhor caracterizado, pode se operar no momento da cristalização do rabdofânio ou mesmo anteriormente, por ocasião da passagem dos ETR para a solução, pois, no interior da perovskita original, o espectro dos ETR não parece variar muito de um cristal para outro. $\mathrm{O} \mathrm{Ce}$ e o $\mathrm{Nd}$ parecem correlacionáveis com o Ca, enquanto La e Pr (este último elemento não aparece na Tab. 4, pelo fato de ter sido dosado com menor precisão) têm um comportamento diferente. Ao contrário do que foi mostrado por Banfield \& Eggleton (1989), em Tapira não se observa um empobrecimento sistemático em Ce no mineral. Por fim, assinala-se que Valarelli (1971) e Carvalho (1974) mencionam o rabdofânio como constituinte do minério da Jazida de Catalão, e Mariano (1989) a brockita no minério de Tapira, sem entretanto fornecerem a caracterização precisa desses minerais.

Comentários sobre a evolução observada Para finalizar, algumas considerações devern ser tecidas sobre a natureza das reações e fluidos que conduziram à paragênese observada neste estágio intermediário de evolução. No que concerne à perovskita, uma simples reação de hidrólise, a temperatura e pressão ambiente, e com soluções que percolem um perfil laterítico, poderia explicar sua transformação para anatásio: $\mathrm{CaTiO}_{3}+2 \mathrm{H}+\mathrm{5} \mathrm{Ca}^{2+}+\mathrm{TiO}_{2}+\mathrm{H}_{2} \mathrm{O}$. Estudos recentes mostram que a perovskita é termodinamicamente instável em meios aquosos, encontrados nas vizinhanças da superfície (Nesbitt et al 1981, Hayward et al 1983, Myrha et al 1984). Entretanto, o polimorfo $\mathrm{TiO}_{2}$ obtido em alterações experimentais foi a brookita e não o atanásio. Além disso, outras reações que a precedem, levando à precipitação de 
Tabela 5 - Fórmulas estruturais do fosfato do grupo do rabdofânio de Tapira

Table 5 - Structural compositions of the Tapira phosphate of rhabdophane group

\begin{tabular}{|c|c|c|c|c|c|c|c|}
\hline $\mathrm{P}_{2} \mathrm{O}_{5}$ & 29,77 & 30,20 & 29,29 & 28,22 & 31,64 & 29,96 & 32,79 \\
\hline $\mathrm{CaO}$ & 8,08 & 7,81 & 8,28 & 8,65 & 10,11 & 9,61 & 11,26 \\
\hline $\mathrm{La}_{2} \mathrm{O}_{3}$ & 18,77 & 18,43 & 15,80 & 11,87 & 13,54 & 12,57 & 8,65 \\
\hline $\mathrm{Ce}_{2} \mathrm{O}_{3}$ & 12,81 & 14,62 & 16,69 & 17,28 & 19,53 & 20,05 & 24,62 \\
\hline $\mathrm{Nd}_{2} \mathrm{O}_{3}$ & 4,93 & 6,57 & 7,05 & 6,85 & 8,40 & 8,17 & 10,55 \\
\hline $\mathrm{Y}_{2} \mathrm{O}_{3}$ & 0,84 & 0,48 & 0,57 & 0,62 & 0,55 & 0,95 & 0,52 \\
\hline SrO & 0,34 & 0,26 & 0,35 & 0,33 & 0,19 & 0,57 & 0,06 \\
\hline $\mathrm{ThO}_{2}$ & 0,35 & - & - & - & $\cdot$ & 0,04 & - \\
\hline Total & 75,89 & 78,37 & 78,03 & 73,82 & 83,96 & 81,92 & 88,45 \\
\hline $\mathrm{p}^{5+}$ & 1,09 & 1,08 & 1,06 & 1,07 & 1,06 & 1,04 & 1,05 \\
\hline $\mathrm{Ca}^{2+}$ & 0,37 & 0,35 & 0,38 & 0,41 & 0,43 & 0,42 & 0,46 \\
\hline $\mathrm{La}^{3+}$ & 0,30 & 0,29 & 0,25 . & 0,20 & 0,20 & 0,19 & 0,12 \\
\hline $\mathrm{Ce}^{3+}$ & 0,20 & 0,23 & 0,26 & 0,28 & 0,28 & 0,30 & 0,34 \\
\hline $\mathrm{Nd}^{3+}$ & 0,08 & 0,10 & 0,11 & 0,11 & 0,12 & 0,12 & 0,14 \\
\hline$Y^{3+}$ & 0,02 & 0,01 & 0,01 & 0,01 & 0,01 & 0,02 & 0,01 \\
\hline $\mathrm{Sr}^{2+}$ & 0,01 & 0,01 & 0,01 & 0,01 & 0,00 & 0,01 & 0,00 \\
\hline $\mathrm{Th}^{4+}$ & 0,00 & $\cdot$ & - & - & - & 0,00 & - \\
\hline Total & 2,07 & 2,07 & 2,09 & 2,10 & 2,10 & 2,12 & 2,12 \\
\hline $\mathrm{O}^{2-}$ & 4,00 & 4,00 & 4,00 & 4,00 & 4,00 & 4,00 & 4,00 \\
\hline $\mathrm{p}^{5+}$ & 1,00 & 1,00 & 1,00 & 1,00 & 1,00 & 1,00 & 1,00 \\
\hline $\mathrm{Ca}^{2+}$ & 0,34 & 0,33 & 0,36 & 0,39 & 0,40 & 0,41 & 0,43 \\
\hline $\mathrm{La}^{3+}$ & 0,27 & 0,27 & 0,24 & 0,18 & 0,19 & 0,18 & 0.11 \\
\hline $\mathrm{Ce}^{3+}$ & 0,19 & 0,21 & 0,25 & 0,26 & 0,27 & 0,29 & 0,32 \\
\hline $\mathrm{Nd}^{3+}$ & 0,07 & 0,09 & 0,10 & 0,10 & 0,11 & 0,12 & 0,14 \\
\hline$Y^{3+}$ & 0,02 & 0,01 & 0,01 & 0,01 & 0,01 & 0,02 & 0,01 \\
\hline $\mathrm{Sr}^{2+}$ & 0,01 & 0,01 & 0,01 & 0,01 & 0,00 & 0,01 & 0,00 \\
\hline $\mathrm{Th}^{4+}$ & 0,00 & - & - & - & - & 0,00 & - \\
\hline Total & 1,90 & 1,91 & 1,96 & 1,96 & 1,98 & 2,03 & 2,02 \\
\hline Carga & 7.36 & 7,40 & 7,52 & 7,48 & 7,55 & 7,66 & 7,63 \\
\hline
\end{tabular}

calcita e titanita, são suscetíveis de intervir se as soluções são suficientemente concentradas em $\mathrm{CO}_{2} \mathrm{e}$

$$
\mathrm{CaTiO}_{3}+\mathrm{SiO}_{2 \mathrm{aq}} \lessgtr: \mathrm{CaTiSiO}_{5} \mathrm{e} \mathrm{CaTiO}_{3}+\mathrm{CO}_{2} \lessgtr: \mathrm{TiO}_{2}+\mathrm{CaCO}_{3}
$$

O itinerário exato entre a perovskita e o anatásio em Tapira não está, portanto, ainda perfeitamente estabelecido.

Com relação à apatita, uma reação de rydrólise entre a apatita primária e soluções pode também ser invocada para explicar sua corrosão e a precipitação simultânea de apatita secundária e rabdofânio; em meio ácido, a reação pode ser escrita:

$$
\mathrm{Ca}_{5}\left(\mathrm{PO}_{4}\right)_{3} \mathrm{~F}+6 \mathrm{H}^{+} \lessgtr 5 \mathrm{Ca}^{2+}+3 \mathrm{H}_{2} \mathrm{PO}_{4}^{-}+\mathrm{F}^{-}
$$

Parece, entretanto, que soluções fortemente ácidas (ou alcalinas), pouco comuns nos meios de alteração superficiais, seriam necessárias para que quantidades importantes de fosfatos fossem liberadas para o meio ambiente (Lindsay \& Vlek 1977). Além disso, a precipitação de apatita secundária rica em flúor é indício evidente de aportes externos de flúor.

Circulações hidrotermais poderiam, portanto, ter favorecido as transformações observadas. A este respeito, é interessante notar que perovskita completamente transformada em anatásio foi observada nas jazidas de Catalão, a $400 \mathrm{~m}$ de profundidade, fora do ambiente da alteração meteórica (Gierth et al. 1985).

Neste estudo essencialmente mineralógico e petrográfico, nada mais pode se dizer sobre a termodinânica desses microssistemas geoquímicos complexos e pouco conhecidos. Entre- tanto, pode-se notar que, quaisquer que sejam a origem e a natureza das soluções que percolaram os materiais, sua circulação não promoveu a mobilização do Fe e Ti e mobilizou fracamente os ETR. Isto tende a mostrar, levando-se em conta o caráter anfótero do $\mathrm{Ti}$, o papel dos complexantes $\left(\mathrm{F}, \mathrm{CO}_{3}{ }^{2+}\right.$ etc.) na mobilização dos ETR (Humphris 1984) e da própria solubilidade dos fosfates de ETR (Vieillard \& Tardy 1984, Meintzer \& Mitchell 1988), que as soluções não poderiam ter sido, nem excessivamente alcalinas, nem extremamente ácidas e nem fortemente concentradas em flúor e em $\mathrm{CO}_{2}$. É, também, importante notar que a associação geoquímica que existe na rocha não-alterada entre titânio e elementos terras raras se mantém no decorrer da evolução; assim, uma associação cristaloquímica Ti-ETR no retículo da perovskita original, sucede, após transformação, uma associação mineralógica rabdofânio-anatásio, nos pseudomorfos que derivam da perovskita.

COMPORTAMENTO DOS ETR NA FÁCIES FINAL DE ALTERAÇÃO (ZONA 2 - RICA EM TITÂNIO) Análise petrográfica e mineralógica $A$ rocha castanhoamarelada em seu conjunto e com fraturação muito irregular é ligeiramente menos densa e mais coerente que a existente na fácies anterior. Ela se apresenta a olho nu como um aglomerado vacuolar de cristais cinza automorfos de anatásio e cinza-escuro xenomorfos de magnetita, de dimensões milimétricas a centimétricas, relativamente imbricados, e recobertos e cimentados por finas capas esverdeadas ou amareladas (Foto 11). Algumas zonas marrons ou avermelhadas, mais friáveis, de magnetita alterada são visíveis no conjunto. Existe uma boa conservação da textura primitiva da rocha, estando anatásio e magnetita associados como na rocha original, se bem que certos deslocamentos (abertura e fechamento de fraturas, rotação de grãos etc.) tiveram lugar após o desaparecimento de apatita, cujos grandes poros irregulares constituem seu único vestígio.

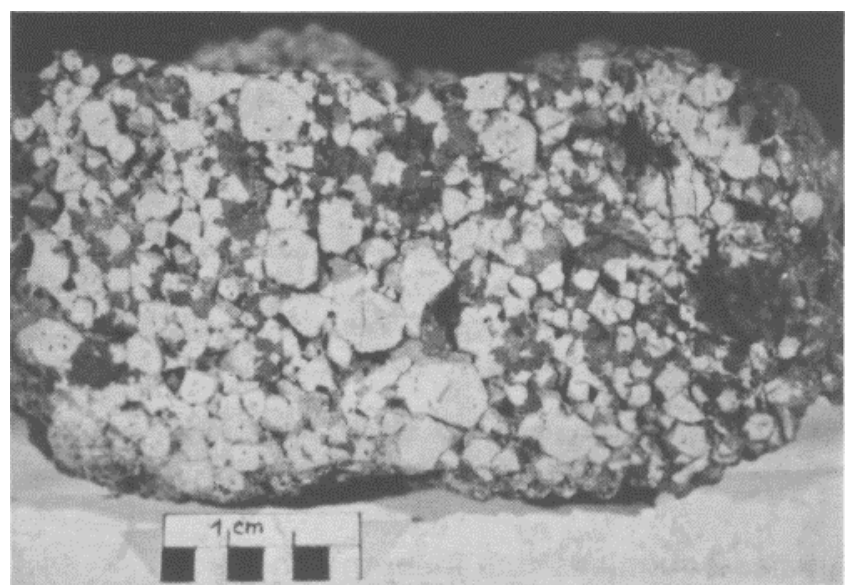

Foto 11 - Fácies final de alteração. Rocha rica em anatásio (cristais automorfos, cinza-claros) e magnetita (cristais xenomorfos, cinza-escuros). A porosidade está relacionada, principalmente, à dissolução da apatita

Photo 11 - Advanced stage of alteration of parental rock constituted by anatase (white crystals) and magnetite (dark crystals). Porosity resulted from apatite dissolution

O exame microscópico confirma o desaparecimento total da apatita primária e secundária. $\mathrm{O}$ anatásio, liberado de suas inclusões de apatita e freqüentemente recortado por fissuras bem abertas, parece "flutuar" em um tecido ferruginoso muito poroso e com poros somente parcialmente preenchidos. Os produtos ferruginosos, às vezes organizados em depósitos zonados, ligam os cristais de anatásio entre si e tendem, localmente, a epigenizá-los (Foto 12). Estes produtos parecem, 
em sua maior parte, provenientes da alteração de magnetita. Um fato notável é a deposição sistemática nos vazios dos critais de anatásio e comumente também ao seu redor ou ainda em certos poros do plasma ferruginoso, de encrustamentos cristalinos rendados, formados pela justaposição de inúmeros pequenos cristais de coloração cinza-clara em LN e LP e apresentando seções triangulares de dimensões de 5 um no máximo (Fotos 13 e 14). Estes cristais, como discutido adiante, foram identificados como sendo um fosfato do grupo da crandallita, quimicamente intermediário entre a crandallita e a florencita. $\mathrm{O}$ rabdofânio, que no estádio precedente forrava as cavidades do anatásio, é aqui dificilmente visível. Somente ao MEV, em imagens obtidas por elétrons retro-difundidos é que foi possível assinalar sua presença: aparecem, na maior parte das vezes, separados de seu suporte, deformados, fragmentados e preenchidos inteiramente pela florencita que os aprisionam; parece, portanto, que se encontram em vias de dissolução e de epigenização pelo fosfato do grupo da crandallita. Além disso, uma fina camada de anatásio de alguns $\mu \mathrm{m}$ de espessura e de textura diferente da do anatásio encontrado no estágio precedente, mas de composição sensivelmente igual, se interpõe, comumente, entre os depósitos de florencita e as paredes dos vazios do anatásio (Foto 15). Tudo leva a supor que as soluções que eliminaram a apatita e depositaram o fosfato do grupo da crandallita foram igualmente responsáveis pela dissolução parcial do fosfato do grupo do rabdofânio e do anatásio.

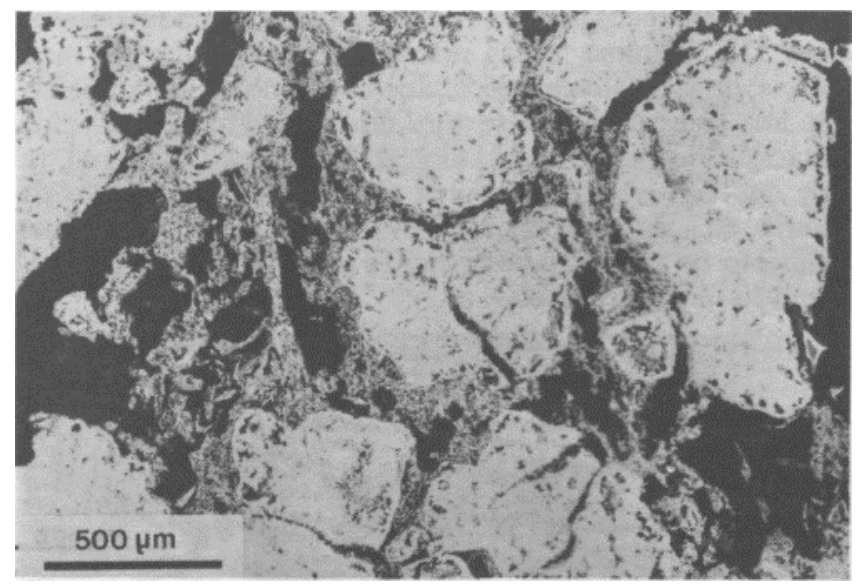

Foto 12 - Fotomicrografia obtida em M.E.V. (elétrons retrodifundidos) mostrando anatásio fissurado, envolvido por um plasma constituído por oxi-hidróxidos de ferro e fosfato do grupo da crandallita

Photo 12 - Back-scattering image (S.E.M.) of anatase envolved by a plasmic material (Fe oxi-hydroxides and phosphate of crandallite group)

Análises químicas das fases neoformadas Anatásio e plasma ferruginoso Quimicamente, não aparecem diferenças significativas entre a composição do anatásio desta fácies (anatásio primário ou reprecipitado) e do existente no estágio anterior. Quanto ao plasma ferruginoso, os ETR não foram detectados fora das zonas onde ocorre o fosfato.

Fosfato do grupo da crandallita Aparece na forma de agregados de cristais romboédricos. Estes cristais são sempre muito pequenos e fortemente associados ao anatásio ou aos depósitos ferruginosos. Dissimulam, às vezes, cristais do fosfato do grupo do rabdofânio, sendo dificilmente separados, o que provoca dificuldades analíticas.

Nos espectros de difração de raios $\mathrm{X}$ de pó de misturas (fosfato do grupo da crandallita + anatásio + fosfato do grupo do rabdofânio) aparecem raias a 5,64;2,92;2,16, 1,$74 ; 2,21 ; 1,43 \AA$ que correspondem mais às da florencita-(Ce), (La) ou (Nd) (Lefebvre \& Gasparrini 1980) que às dos outros fosfatos do grupo da crandallita. Estes espectros não são, entretanto, de boa qualidade, e não oferecem segurança para uma perfeita identificação desse mineral. As análises realizadas na microssonda (Tab. 6) permitiram, entretanto, esclarecer esta indefinição.

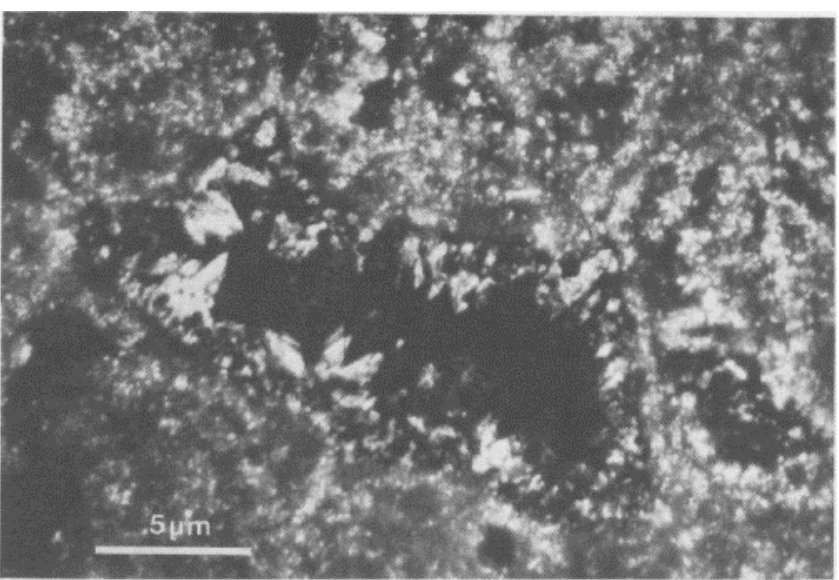

Foto 13 - Microgeodos com cristais romboédricos de fosfato do grupo da crandallita. (Nicóis $X$ )

Photo 13 - Rhomboedric crystals of phosphate of the crandallite group in microgeodes. (Nicols X)

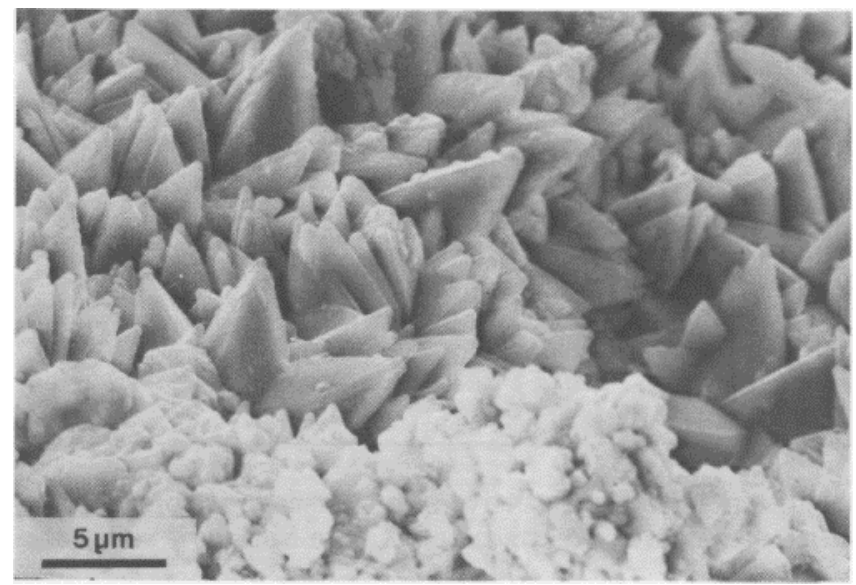

Foto 14 - Formas romboédricas exibidas por cristais de fosfato do grupo da crandallita, vistas em M.E.V

Photo 14 - Rhomboedric crystals of phosphate of crandallite group (S.E.M.)

Pelas mesmas razões aventadas para o fosfato do grupo do rabdofânio, na tabela 6 vê-se também que as análises não somam $100 \%$ (perdas de água ao redor de $170^{\circ} \mathrm{C}$, existência de poros nos agregados dos cristais soldados). Constata-se que $\mathrm{Ca}, \mathrm{Sr}, \mathrm{Fe}, . .$. , acompanham os ETR no mineral, indicando que não se trata de uma florencita pura, o que é aliás comum à maior parte dos minerais descritos como florencita (MacKie 1962, Vlasov 1966, Lefebvre \& Gasparrini 1980, Pouliot \& Hofmann 1981, Nriagu \& Moore 1984, Banfield \& Eggleton 1989).

Para o cálculo da fórmula estrutural, levou-se em consideração a fórmula dos minerais do grupo de crandallita que é do tipo $\mathrm{AB}_{3}\left(\mathrm{XO}_{4}\right)_{2}(\mathrm{OH}, \mathrm{F})_{5-6}\left(\mathrm{H}_{2} \mathrm{O}\right)_{1-0}$, onde $\mathrm{A}=\mathrm{Ca}, \mathrm{Ba}, \mathrm{Sr}$, ETR, $\mathrm{Pb}, \mathrm{Bi}, \mathrm{Th}, . . ; \mathrm{B}=\mathrm{Al}, \mathrm{Fe}^{3+} ; \mathrm{X}=\mathrm{P}, \mathrm{Si}, \mathrm{As}, \mathrm{S}$ (Fleischer 1987). Para $\mathrm{X}=\mathrm{P}$, que é o caso para o mineral de Tapira, pois Si ocorre em porcentagens bem reduzidas e $\mathrm{S}$ e As não foram detectados, o cortejo de cations observados permite selecionar entre a florencita- $(\mathrm{Ce}),(\mathrm{La})$ e $(\mathrm{Nd})$ : $(\mathrm{ETR}) \mathrm{Al}_{3}\left(\mathrm{PO}_{4}\right)_{2}(\mathrm{OH})_{6}$; crandallita: $\mathrm{CaAl}_{3}\left(\mathrm{PO}_{4}\right)_{2}(\mathrm{OH})_{5} \cdot \mathrm{H}_{2} \mathrm{O} ;$ goiasita: $\mathrm{SrAl}_{3}\left(\mathrm{PO}_{4}\right)_{2}(\mathrm{OH})_{5} \cdot \mathrm{H}_{2} \mathrm{O}$; gorceixita: $\mathrm{BaAl}_{3}\left(\mathrm{PO}_{4}\right)\left(\mathrm{PO}_{3} \mathrm{OH}\right)(\mathrm{OH})_{6}$. Os cálculos efetuados sobre base de $2 \mathrm{P}$, devido a incerteza sobre o número de $\mathrm{OH}$ na malha, necessitam, como para o fosfato do grupo do rabdofâ- 


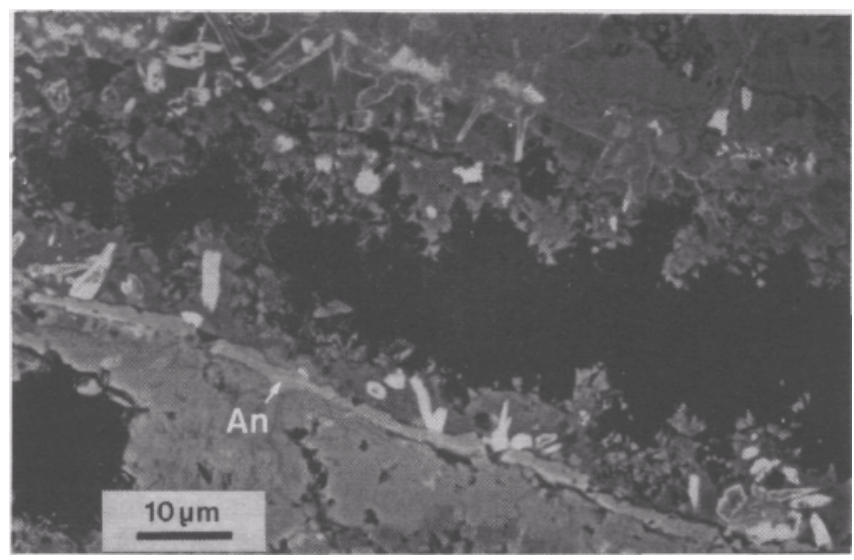

Foto 15 - Fotomicrografia obtida em M.E.V. (elétrons retrodifundidos) de cristais de fosfato do grupo do rabdofânio (brancos), parcialmente dissolvidos e epigenizados por cristais de fosfato do grupo da crandallita (cinza-escuros). Vê-se, também, uma nítida deposição de anatásio (An) Photo 15 - Back scattering image (S.E.M.) of phosphate of rhabdophane group crystals (white) partially dissolved and substituted by epigenic phosphate of crandallite group crystals (dark gray). Note the late deposition of secondary anatase $(\mathrm{An})$

Tabela 6 - Análises químicas (microssonda eletrônica) do fosfato do grupo da crandallita de Tapira

Table 6 - Microprobe analises of the Tapira phosphate of crandallite group

\begin{tabular}{lcrrrrr}
\hline & $\%$ & $\%$ & $\%$ & $\%$ & $\%$ & $\%$ \\
\hline $\mathrm{CaO}$ & 5,54 & 4,43 & 4,96 & 4,44 & 4,45 & 5,72 \\
$\mathrm{BaO}$ & 0,80 & 0,14 & 0,27 & 0,04 & 0,24 & 0,98 \\
$\mathrm{SrO}$ & 3,26 & 2,25 & 1,66 & 0,99 & 0,86 & 0,46 \\
$\mathrm{SiO}_{2}$ & 0,12 & 0,07 & 0,18 & 0,27 & 0,04 & 0,09 \\
$\mathrm{Al}_{2} \mathrm{O}_{3}$ & 29,00 & 31,65 & 29,84 & 30,27 & 31,21 & 32,25 \\
$\mathrm{Fe}_{2} \mathrm{O}_{3}$ & 2,39 & 1,48 & 2,57 & 1,71 & 1,33 & 1,33 \\
$\mathrm{TiO}_{2}$ & 0,57 & 0,14 & 1,20 & 0,31 & 0,32 & 0,11 \\
$\mathrm{UO}_{3}$ & - & 0,00 & 0,00 & 0,00 & 0,00 & 0,00 \\
$\mathrm{ThO}_{2}$ & - & 0,00 & 0,00 & 0,00 & 0,16 & 0,00 \\
$\mathrm{La}_{2} \mathrm{O}_{3}$ & 3,04 & 5,71 & 3,50 & 5,34 & 4,28 & 3,63 \\
$\mathrm{Ce}_{2} \mathrm{O}_{3}$ & 4,87 & 6,95 & 6,15 & 6,86 & 8,77 & 6,68 \\
$\mathrm{Nd}_{2} \mathrm{O}_{3}$ & 1,73 & 2,38 & 2,56 & 2,56 & 3,63 & 2,67 \\
$\mathrm{Y}_{2} \mathrm{O}_{3}$ & 0,00 & 0,11 & 0,12 & 0,24 & 0,10 & 0,13 \\
$\mathrm{P}_{2} \mathrm{O}_{5}$ & 27,21 & 26,00 & 24,58 & 24,00 & 23,88 & 26,04 \\
$\mathrm{Total}$ & 78,53 & 81,31 & 77,59 & 77,03 & 79,27 & 80,09 \\
\hline
\end{tabular}

nio, de algumas aproximações: a. Ti e Si foram considerados como pertencentes ao anatásio que suporta os cristais, não sendo por isso levados em consideração; b. O Ba também não foi levado em consideração pois as dosagens, além de incertas, indicavam sempre teores muitos baixos, apesar de ser possível sua inclusão, em pequenas proporções, no retículo do mineral; c. Todo o ferro dosado foi considerado como pertencente à florencita, apesar de que uma parte deva pertencer ao anatásio. Entretanto, esta percentagem é muito pequena, no máximo 3\% de $\mathrm{Fe}_{2} \mathrm{O}_{3}$ para $100 \% \mathrm{TiO}_{2}$; d. Os valores encontrados para $\mathrm{Al}_{2} \mathrm{O}_{3}$ levam o total de cations para a posição $\mathrm{B}$ acima de 3 . A explicação possível é que parte do alumínio esteja na forma de oxido de alumínio amorfo ou gibbsita (não detectada nos estudos) e misturada aos cristais de florencita. Portanto, foram subtraídas dos valores encontrados na análise de $\mathrm{A}_{2} \mathrm{O}_{3}$, as quantidades necessárias para se chegar ao total teórico de três cations para a malha na posição $\mathrm{B}$ (subtração de $1 \mathrm{a} 6 \% \mathrm{Al}_{2} \mathrm{O}_{3}$ ). Os resultados destes cálculos reunidos na tabela 7 permitem as seguintes observações:

- A soma de cations na posição A é próxima de 1 (0,98 $1,14)$, como prevê a fórmula teórica, sendo que o Ca se apresenta praticamente em igualdade com ETR ( $\Sigma$ ETR: 0,30 $\bullet 0,54)$. O Sr possui importância secundária.

- Existe um déficit de carga catiônica em relação à carga aniônica teórica de uma malha de florencita: $\left(8 \mathrm{O}+6 \mathrm{OH}^{-}\right)$ $=22$ cargas negativas. Isto está ligado à entrada de $\mathrm{Ca}^{2+} \mathrm{e}$ $\mathrm{Sr}^{2+}$, no retículo, em substituição aos $\mathrm{ETR}^{3+}$. É possível, sendo o meio certamente oxidante, que a compensação de carga se faça, nese caso, pela oxidação do cério: $\mathrm{Ce}^{3+} \rightarrow \mathrm{Ce}^{4+}$ de acordo com Burt (1989), os raios iônicos são próximos; porém, isto não é suficiente. Parece, então, provável, assim como já discutido para o fosfato do grupo do rabdofânio, que $(\mathrm{OH})$ suplementares devem integrar o retículo do mineral.

Tabela 7 - Fórmulas estruturais do fosfato do grupo da crandallita de Tapira

Table 7 - Structural compositions of the Tapira phosphate of crandallite group

\begin{tabular}{lrrrrrr}
\hline $\mathrm{P}_{2} \mathrm{O}_{5}$ & 27,21 & 26,00 & 24,58 & 24,00 & 23,88 & 26,04 \\
$\mathrm{Al}_{2} \mathrm{O}_{3}$ & 27,73 & 27,08 & 24,82 & 24,77 & 24,87 & 27,25 \\
$\mathrm{Fe}_{2} \mathrm{O}_{3}$ & 2,39 & 1,48 & 2,57 & 1,71 & 1,33 & 1,33 \\
$\mathrm{Ce}_{2} \mathrm{O}_{3}$ & 4,87 & 6,95 & 6,15 & 6,86 & 8,77 & 6,68 \\
$\mathrm{La}_{2} \mathrm{O}_{3}$ & 3,04 & 5,71 & 3,50 & 5,34 & 4,28 & 3,63 \\
$\mathrm{Nd}_{2} \mathrm{O}_{3}$ & 1,73 & 2,38 & 2,56 & 2,56 & 3,63 & 2,67 \\
$\mathrm{Y}_{2} \mathrm{O}_{3}$ & - & 0,11 & 0,2 & 0,24 & 0,10 & 0,13 \\
$\mathrm{ThO}_{2}$ & - & - & - & - & 0,16 & - \\
$\mathrm{CaO}$ & 5,54 & 4,43 & 4,96 & 4,44 & 4,45 & 5,72 \\
$\mathrm{SrO}$ & 3,26 & 2,25 & 1,66 & 0,99 & 0,86 & 0,46 \\
$\mathrm{Total}$ & 75,77 & 76,39 & 70,92 & 70,91 & 72,33 & 73,91 \\
& & & & & & \\
$\mathrm{P}$ & 2,00 & 2,00 & 2,00 & 2,00 & 2,00 & 2,00 \\
$\mathrm{Al}+3$ & 2,84 & 2,90 & 2,81 & 2,87 & 2,90 & 2,91 \\
$\mathrm{Fe}+3$ & 0,16 & 0,10 & 0,19 & 0,13 & 0,10 & 0,09 \\
$\mathrm{Ce}+3$ & 0,15 & 0,23 & 0,22 & 0,25 & 0,32 & 0,22 \\
$\mathrm{La}+3$ & 0,10 & 0,19 & 0,12 & 0,19 & 0,16 & 0,12 \\
$\mathrm{Nd}+3$ & 0,05 & 0,08 & 0,09 & 0,09 & 0,13 & 0,09 \\
$\mathrm{Y}+3$ & - & 0,01 & 0,01 & 0,01 & 0,01 & 0,01 \\
$\mathrm{Th}+4$ & - & - & - & - & 0,00 & - \\
$\mathrm{Ca}+2$ & 0,52 & 0,43 & 0,51 & 0,47 & 0,47 & 0,56 \\
$\mathrm{Sr}+2$ & 0,16 & 0,12 & 0,09 & 0,06 & 0,05 & 0,02 \\
$\mathrm{Total}$ & 5,98 & 6,06 & 6,04 & 6,07 & 6,13 & 6,02 \\
$\mathrm{Carga}$ & 21,26 & 21,62 & 21,50 & 21,68 & 21,87 & 21,48 \\
\hline & & & & & & \\
\hline
\end{tabular}

Desta forma, a fórmula estrutural média e aproximada do mineral de Tapira, considerando que todo o cério encontra-se como $\mathrm{Ce}^{3+}$, pode ser escrita:

\section{$\left(\mathrm{Ca}_{0,49} \mathrm{TR}_{0,42} \mathrm{Sr}_{0,08} \ldots\right)\left(\mathrm{Al}_{2,87} \mathrm{Fe}_{0,13}^{3+}\left(\mathrm{PO}_{4}\right)\left(\mathrm{PO}_{3,43}(\mathrm{OH})_{0,57}\right)(\mathrm{OH})_{6}\right.$}

Este mineral é quimicamente intermediário entre a florencita - (TR)A1 $1_{3}\left(\mathrm{PO}_{4}\right)_{2}(\mathrm{OH})_{6}$ e a crandallita - $\mathrm{CaAl}_{3}\left(\mathrm{PO}_{4}\right)_{2}(\mathrm{OH})_{5}$. $\mathrm{H}_{2} \mathrm{O}$, ou mais corretamente, segundo Blount (1974) $\mathrm{CaAl}_{3}\left(\mathrm{PO}_{3}\left(\mathrm{O}_{0,5}\right)\right)_{2}(\mathrm{OH})_{6}$. Esses minerais são comumente encontrados em certas séries sedimentares ou em alterações de pegmatites e jazidas minerais. Tendo em vista que uma solu- 
cão sólida é teoricamente possível entre a crandallita e a florencita, pois elas pertencem ao mesmo grupo pontual (R3m) (Blount, 1974, Simone et al 1985), o mineral de Tapira poderia ser considerado como um termo intermediário desta solução sólida. Deve ser notado, porém, que, ao contrário do que ocorre na serie isomorfa semelhante "goiasita-florencita", não foram encontradas na literatura as provas da existência na natureza e nem a caracterização cristaloquímica precisa de minerais desta série. Além disso, a ausência de um espectro de difração de raios X completo e de boa qualidade para o mineral de Tapira leva a considerar uma outra hipótese; Cowgill \& Hutchinson (1963) e Blount (1974) mostraram a existência de minerais chamados "crandallita triclínica", cujos espectros de difração de raios X não diferem muito dos da crandallita s.s. $e$ de outros minerais da família e cuja composição aproxima-se da do mineral de Tapira $(\mathrm{Ca}, \mathrm{Sr}, \mathrm{ETR}, .$. no sítio A). Assim, este mineral poderia pertencer a esse grupo ainda mal definido. Lemos \& Costa (1987) encontraram recentemente, na Jazida de Maicuru, fosfates secundários que, possivelmente, aproximam-se do mesmo mineral.

Finalmente, assinala-se que é a crandallita, mas não um fosfato intermediário entre florencita e crandallita, o mineral citado por todos os autores como constituinte dos minérios de Tapira.

Comentários sobre a evolução observada Apesar dos estudos sobre a paragênese e os fluidos envolvidos na evolução não estarem totalmente concluídos, algumas observações podem ser feitas:

- O desaparecimento da apatita e sua substituição por fosfatos aluminosos é um fenômeno classicamente observado nas jazidas de fosfatos sedimentares submetidos a alteração ferralítica (Flicoteaux 1982). A evolução observada em Tapira, neste estágio final, poderia então resultar, simplesmente, de uma longa hidrólise dos materiais, por águas meteóricas, sem intervenção, como no caso do estágio precendente, de fluidos hidrotermais.

- Uma parte dó alumínio e do ferro contidos originalmente na flogopita, no diopsídio e na magnetita acabam por se encontrar na florencita neoformada, bem como nas cutanas ferruginosas. Estes elementos são, portanto, móveis nas soluções de alteração, da mesma forma, porém de uma maneira menos evidente, que o titânio. Isto necessita ainda de explicação e coloca, sobretudo para o Ti, o problema do eventual papel dos agentes complexantes nesta mobilização (flúor da apatita).

- Uma certa mobilização dos ETR pode ser igualmente constatada, pois a neoformação de florencita não se limita à substituição de antigos minerais portadores (rabdofânio e apatita). Os ETR (e o Sr) liberados pela hidrólise desses minerais puderam, certamente, circular nas soluções fosfatadas de alteração antes de serem aprisionados na precipitação do fosfato do grupo da crandallita. Esta mobilização é, entretanto, limitada, pois é ainda no interior do anatásio, principal portador de ETR no estágio precedente, que se cristalizou o fosfato do grupo da crandallita e que se localiza ainda o estoque essencial de ETR dos materiais, sob a forma de fosfato do grupo do rabdofânio residual e fosfato do grupo da crandallita. A correlação titânio - ETR, observada desde o início, mantém-se ainda neste estágio de evolução. Esta associação, constatada na escala da lâmina delgada, verifica-se também na escala de jazida, o que bem atesta seu elevado grau de generalidade em Tapira; as correlações $\left(\mathrm{TR}_{2} \mathrm{O}_{3}-\mathrm{TiO}_{2}\right) \mathrm{e}\left(\mathrm{P}_{2} \mathrm{O}_{5}-\mathrm{TR}_{2} \mathrm{O}_{3}\right)$ calculadas sobre um conjunto de 72 amostras representativas da jazida (quatro sondagens que atravessam as três zonas estudadas) forneceram um coeficiente de correlação linear: $\mathrm{R}_{(\mathrm{Ti}-\mathrm{TR})}=+0,75$, enquanto $\mathrm{R}_{(\mathrm{P}-\mathrm{TR})}=+0,13$.

- Uma última observação concerne aos espectros respectivos em ETR dos fosfatos secundários de ETR (Tabs. 5 e 7). Pode-se notar que o Ce é o elemento dominante na florencita, enquanto o La predomina às vezes no fosfato do grupo do rabdofânio. Nota-se, também, que a relação $\mathrm{Y}_{2} \mathrm{O}_{3} / \sum \mathrm{TR}_{2} \mathrm{O}_{3}$ é mais baixa no fosfato do grupo da crandallita $(0,010$ contra $0,016)$ e que, por conseguinte, um certo fracionamento dos ETR se opera na passagem de um mineral para outro. É notável que este fracionamento (aumento da parte relativa dos ETR leves e da parte de Ce no fosfato do grupo da crandallita) é análogo ao evidenciado por diferentes autores na alteração de outros minerais (Meintzer \& Mitchell 1988) assim como na escala do perfil (Duddy 1980, Bonnot-Courtois 1981, Sigolo et al. 1987, Fortin 1989, Banfield \& Eggleton 1989). As explicações para este fracionamento seriam: a possibilidade que somente o Ce apresenta, em relação aos outros ETR, de passar em meio oxidante ao estado tetra valente e, conseqüentemente, adquirir uma mobilidade hidrolítica bem menor que o $\mathrm{Ce}^{3+}$; a maior estabilidade dos complexos de ETR pesados em relação aos leves, o que sem dúvida favorece a migração preferencial dos primeiros.

CONCLUSÕES Os estudos petrográficos e mineralógicos realizados nos materiais de alteração da Jazida de Tapira, se bem que limitados aos primeiros estágios da evolução supérgena, forneceram importantes informações sobre o itinerário geoquímico dos ETR e do Ti nos meios superficiais, e permitiram as seguintes conclusões:

1. Ao contrário do que tem sido descrito para essa jazida e do que é comumente encontrado em outros locais, a perovskita, e não a apatita, é o principal portador primário de ETR em Tapira.

2. Em Tapira, o estoque inicial de ETR se mantém durante a evolução supérgena, principalmente através de seu aprisionamente em diferentes fases mineralógicas pertencentes a uma sequiência de fosfatos neoformados que lhe serve de portadora em direção à superfície.

3. A riqueza em Ca do meio, assim como sua aluminização progressiva no decorrer da alteração, reflete-se na natureza das sucessivas neoformações. Assim, há um fosfato de ETR não-aluminoso: (Ca ETR) $\mathrm{PO}_{3}(\mathrm{O} \mathrm{OH})$. $\mathrm{xH}_{2} \mathrm{O}$, do grupo do rabdofânio, formado em um primeiro estádio de evolução, sucede um fosfato de ETR aluminoso: $(\mathrm{CaETR})(\mathrm{AlFe})_{3}\left(\mathrm{PO}_{4}\right)\left(\mathrm{PO}_{3}\right)(\mathrm{O} \mathrm{OH})(\mathrm{OH})_{6}$ do grupo da crandallita.

4. Existe, em diferentes escalas analisadas, da lâmina delgada à jazida, uma forte associação entre o titânio e os ETR. A razão é cristaloquímica no início, pois a perovskita é o principal portador de ETR, e se torna físico-química, em seguida, pois o anatásio pseudomórfico sobre a perovskita constitui o meio preferencial de fixação dos fosfatos de ETR neoformados.

5. Uma lixiviação diferencial de Ce e ETR pesados parece se manifestar no decorrer da alteração: o Ce tende a se concentrar, e os ETR pesados a serem lixiviados. Estes resultados necessitam, entretanto, de uma melhor definição, apesar de concordarem com observações feitas por outros autores em diferentes locais.

6. Nos estágios de evolução estudados, oxi-hidróxidos de ferro e argilo-minerais neoformados têm um papel secundário na fixação de ETR. É possível que o mesmo não ocorra no latossolo somital do megaperfil laterítico de Tapira, onde estes minerais são bem mais abundantes. Todos estes problemas, assim como o futuro dos fosfatos secundários de ETR nos estágios ulteriores de alteração constituem o tema de um estudo em curso.

Agradecimentos Os autores agradecem à direção da Companhia Vale do Rio Doce e da FOSFERTIL pela colaboração prestada e pela autorização concedida para os estudos de suas jazidas; exprimem, também, sua profunda gratidão ao pessoal técnico da Mina de Tapira e em especial aos Drs. Amilcar Souto Jorge, Luiz Antônio Fonseca dos Santos, Paulo 
de Tarso Machado, pela gentileza de sua acolhida e pela ajuda prestada nos trabalhos de campo. Agradecem as críticas e os conselhos de F. Gibert, B. Moine, F. Fontan e J.P. Fortune, que foram de importância fundamental para a realização deste trabalho. Finalmente, gostariam de agradecer também ao CNPq e ao PADCT pela ajuda financeira prestada.

\section{REFERÊNCIAS BIBLIOGRÁFICAS}

ADERCA, B.M. \& TASSEL, Van R. 1971. Le gisement de terres tares de la Karonge (Burundi). Bruxelles, Acad. Roy. Sc. O.M./Classe Sc. Nat., 28(5): $117 \mathrm{p}$.

ATKIN, D.; BASHAM, I.R.; BOWLES, J.F.W. 1983. Tristramite, a new calcium uranium phosphate of the rhabdophane group. Mineral. Mag., 47:393-396.

BAECKER, ML 1983. A mineralização de nióbio no solo residual lateritico e a petrografla das rochas ultramáficas-alcalinas do domo de Catalão I, Goiás. Brasília. 113p. (Dissertação de Mestrado, IG/UnB).

BANFIELD, J.F. \& EGGLETON, R.A. 1989. Apatite replacement and rare earth mobilization, fractionation and fixation during weathering. Clays and Clay Min., 37(2):113-127.

BOUNT, A.M. 1974. The crystal structure of crandallite. Am. Mineral. 59:41-47

BONNOT-COURTOIS, C. 1981. Géochimie des terres rares dans les principaux milieux deformation et de sedimentation des argues. Orsay. 217p. (These Doc. Etat, Universite de Paris XI).

BOWIE, S.H.U. \& HORNE, J.E.T. 1953. Cheralite, a new mineral of the monazite group. Mineral. Mag., 30:93-99.

CARVALHO, W.T. 1974a. Aspectos geológicos e petrográficos do complexo ultramáfico-alcalino de Catalão I, GO. In: CONOR. BRAS. GEOL., 28. Porto Alegre, 1974. Anais... Porto Alegre, SBG. v. 5, p. 107-12\&

CARVALHO, W.T. 1974b. Recursos minerais do complexo ultramáfico-alcalino de Catalão I, GO. In; CONOR. BRAS. GEOL., 28. Perto Alegre, 1974. Anais... Porto Alegre, SBG. v. 6, p. 165-184.

COMPANHIA BRASILEIRA DE METALURGIA E MINERAČ̃̃ 1984. Complexos carbonáticos do Brasil; geologia. São Paulo, CBMM/Dpto. Geol. 44 p.

COWGILL, U.M. \& HUTCHINSON, G.E. 1963. An apparently triclinic dimorph of crandallite from a tropical swamp sediment in El Peten, Guatemala. Am. Mineral, 48:1144-1153.

CRUZ, F.F. \& CHENEY, T.M. 1976. Recursos de fosfato no complexo carbonático de Tapira, MG. In: CONOR. BRAS. GEOL., 29. Ouro Preto, 1976. Anais... Ouro Preto, SBG. v. 1, p. 89-107.

CULLERS, R.L. \& GRAF, J.L. 1984. Rare earth elements in igneous rocks of the continental crust: predominantly basic and ultrabasic rocks. In: HENDERSON, P. ed. Rare earth elements geocheminstry. Amsterdam, Elsevier. p. 237-274.

COSTA, M.L. 1987. Uma contribuição geoquímica ao desenvolvimento do perfil intempérico de Anitápolis (SC). In: CONGR. BRAS. GEOQ., 1. Porto Alegre, 1987, Anais... Porto Alegre, SBGq. v. 2, p. 17-34.

DAWSON, J.B. 1980. Kimberlites and their xenoliths. Berlin, Springer-Verlag. $252 \mathrm{p}$.

DEER, W.A.; HOWIE, R.A.; ZUSSMAN, J. 1962. Rock-forming minerals. 5: non silicates. New York, Willy \& Sons. 371 p.

DEPARTAMENTO NACIONAL DA PRODUÇÃO MINERAL 1984. Geologia do Brasil. Brasília, DNPM/MME. $501 \mathrm{p}$.

DOOLEY.J.R.\& HATHAWAY, J.C. 1961.Two occurences of thorium-bearing minerals with rhabdophane-like structure. Washington, U.S. Geol. Survey Prof. Paper, p. 339-341. (424-C).

DUDDY, I.R. 1980. Redistribution and fractionation of rare earth and other elements in a weathering profile. Chem. Geol., 30:363-381.

FISHER, F.G. \& MEYROWITZ, R. 1962. Brockie, a new calcium thorium phosphate from the wet mountains, Colorado. Am. Mineral., 47:13461355 .

FLEET, A.J. 1984. Aqueous and sedimentary geochemistry of the rare earth elements. In: HENDERSON, P. ed. Rare earth element geochemistry. Amsterdam, Elsevier, p. 343-373.

FLEISCHER, M. 1962. New data on rhabdophane group. Am. Mineral., 47:419-420.

FLEISCHER, M. 1987. Glossary of mineral species. Tucson, Min. Record. $227 \mathrm{p}$.

FLICOTEAUX, R. 1982. Genèse des phosphates alumineux du Senegal occidental Etapes et guides de I'alteration. Mem. Sc. Geol. 67: 229 p.

FORTIN, P. 1989. Mobilisation, fractionnement et accumulation des terres rares lors de l'alteration latéritique de sediments argilo-sableux du basin de Curitiba (Brésil). Poitiers. 235 p. (These Doct., Univesité Poitiers).

GIERTH, E.; LEONARDOS, O.H.; BAECKER, M.L. 1985. Some mineralogical characteristics of the main constituents of the unweathered section of the carbonatite complex Catalão I, Goiás, Brazil. Contrib. Geol. Petr., p. 45-48. (Bol. Esp. SBGM).

GRAMACCIOLI, C.M. 1985. Conoscere i minerali. I radioattivi. Novara, Int. Geogr. Agostini. 96 p.

GRIGOR'EV, D.P. 1965. Ontogeny of minerals. Jerusalem, Israel Program for Scientific Translation. $250 \mathrm{p}$.

GROSSI SAD, J.H. \& TORRES, N. 1971. Geologia e recursos minerais do Complexo de Tapira, Minas Gerais, Brasil. Belo Horizonte, GEOSOL. $68 \mathrm{p}$.
HAYWARD, P.J.; DOERN, F.E.; CECCHETO, E.V.; MITCHELL, S.L. 1983. Leaching studies of natural and synthetic titanite, a potential host for wastes from the reprocessing of Canadian nuclear fuel. Can. Mineral., 21:611-623.

HEINRICH, E.W. 1980. The geology ofcarbonalites. New York, R.E. Krieger. $585 \mathrm{p}$.

HENDERSON, P. 1984. General geochemical properties and abundance of the rare earth elements. In: HENDERSON, P. ed. Rare earth elements geochemistry. Amsterdam, Elsevier. p. 1-32.

HENDERSON, P. 1984. Rare earth element geochemistry. Amsterdam, Elsevier. $510 \mathrm{p}$.

HERRMANN, A.G. 1969. Yttrium and lanthanides. Abundance in common igneous rock types. In: WEDEPOHL, ed. Handbook of geochemistry. 49(E):57-71.

HUMPHRIS, S.E. 1984. The mobility of the rare earth elements in the crust. In: HENDERSON, P. ed. Rare earth element geochemistry. Amsterdam, Elsevier. p. 317-342.

LEFEBVRE, J.J. \& GASPARRINI, C. 1980. Florencite, an occurence in the Zairian Coppergelt. Can. Mineral., 18:301-311.

LEMOS, P.V. \& COSTA, M.L. 1987. Partição das terras raras nos lateritos fosfáticos de Maicuru (PA). In: CONOR., BRAS, GEOQ., 1. Porto Alegre, 1987. Anais... Porto Alegre, SBGq. v. 1, p. 83-102.

LINDENMAYER, Z.G. 1978. A chamitié carbonatica de Tapira e sua mineralização a titânio, fosfato e nióbio. Salvador, UFBa. 37 p. (Dec. mimeografado).

LINDSAY, W.L. \& VLEK, P.L.G. 1977. Phosphate minerals. In: DIXON \& WEED eds. Minerals in soil environments. Madison, Soil Sci. Soc. Amer. p. 639-372.

MacKlE, D. 1962. Goyazite and florencite from two african carbonatites. Mineral. Mag., 33:281-297.

MARIANO, A.N. 1989. Nature of economic mineralization in carbonatites and related rocks. In: BELL, K. ed. Carbonatites genesis and evolution. London, Unwin Hyman. $618 \mathrm{p}$.

MEINTZER, R.E.; MITCHELL, R.H. 1988. The epigene of allanite. Can. Mineral., 26:945-955.

MITCHELL, R.H. 1986. Kimberlites: mineralogy, geochemistry and petrology. New York, Plenum. $441 \mathrm{p}$.

MITCHELL, R. H. \& REED, S.J.B. 1988. Ion microprobe determination of R.E. elements in perovskite from kimberlites and almöites. Mineral Mag., 52:331-339.

MOONEY, R.C.L. 1950. X-ray diffraction study of cerous phosphate and related crystals. I. Hexagonal modification. Acta Cryst.. 3:337-340.

MUIR, J.J.; METSON, J.B.; BANCROFT, G.M. 1984. ${ }^{57} \mathrm{Fe}$ mossbauer spectra of perovskite and titanite. Can. Mineral, 22:689-694.

MUTO, T; MEYROWITZ, R.; POMMER, A. M; MURANO, J. 1959. Ningyoite, a new uranous phosphate minerals from Japan. Am. Mineral, 44:633-650.

MYHRA, S.; SAVAGE, D.; ATKINSON, A.; RIVIERE, J.C. 1984. Surface modification of some titanate minerals subjected to hydrothermal chemical attck. Am. Mineral, 69:902-909.

NASH, P.W. 1984. Phosphate minerals in terrestrial igneous and metamorphic rocks. In: NRIAGY \& MOORE eds. Phosphate minerals. Berlin, Springer-Verlag. p. 215-241.

NESBITT, H.W.; BANCROFT, G.M.; FYFE, W.S.; KARKHANIS, S.N.;

NISHIJIMA, A. 1981. Thermodynamic stability and kinetics of perovskite dissolution. Nature, 289:358-362.

NICKEL, E.H. \& McADAM, R.C. 1963. Niobian perovskite from Oka, Quebec; a new classification from minerals of the perovskite group. Can. Mineral, 7:683-697.

NRIAGU, J.O. \& MOORE, P.B. 1984. Phosphate minerals. Berlin, Springer-Verlag. 442 p.

POULIOT, G. \& HOFMANN, H.J. 1981. Florencite: a first occurrences in Canada. Can. Mineral, 19:535-540.

ROEDER, P.L. 1985. Electron microprobe analysis of minerals for rare earth elements: use of calculed peak-overlap correction. Can. Mineral, 23:263-271.

ROEDER, P.L.; McARTHUR, D.; XIN-PEI MA; PALMER, G.R.; MARIANO, A.N. 1987. Cathadoluminiscence and microprobe study of rare earth elements in apatite. Am. Mineral, 72:801-811.

SAWKA, W.N.; BANFIELD, J.F.; CHAPPELL, B.W. 1986. A weatheringrelated origin of widespread monazite in S-type granites. Geoch. Cos moch. Acta., 50:171-175.

SÍGOLO, J.B.; BOULANGÉ, B.; MULLER, J.P.; SCHIMITT, J.M. 1987. Distribuição de elementos terras raras em um perfil de bauxita lateritica sobre rocha alcalina, Maciço de Passa Quatro (MG). In: CONGR. BRAS. GEOQ., 1. Porto Alegre, 1987.Xnais... Porto Alegre, SBGq. v. 1, p. 71-81.

SIMONE, C.A.; MASCARENHAS, Y.P.; SVISERO, D.P. 1985. Refinamento da estrutura cristalina da florencita pelo método dos mínimos quadrados utilizando amostras policristalinas. Rev. Bras. GeOc., 15(2): 164-169. 
VALARELLI, J. V. 1971. O minério de nióbio, titanio e terras raras de Catalão, GO. São Paulo. 104 p. (Tese de Livre Docência, IG/USP).

VAZ DE MELO, M.T. 1983. Depósitos minerais associados ao complexo alcalino carbonático de Tapira (MG). Belo Horizonte, CVRD. 39 p, (Doc. Mimeografado).

VIEILLARD, P. \& TARDY, Y. 1984. Thermochemical properties of phosphates. In: NRIAGU \& MOORE eds. Phosphate minerals. Berlin, Springer-Verlag. p. 171-198.

VLASOV, K.A. 1966. Geochemistry and mineralogy of rare elements and genetic types of their deposits. Mineralogy of rare elements. Jerusalem, Israel Program for Scientific Translation. 933 p. (v. II).
WALENTA, Von K. 1979. Chukhrovite-(Ce) und Rhabdophan-(Ce) aus der Grube Clara bei Oberwolfach im mittleren Schwarzwald. Chem. Erde, 38:331-339.
MANUSCRITO A657

Recebido em 27 de abril de 1990

Revisão do autor em 9 de janeiro de 1991 Revisão aceita em 5 de fevereiro de 1991 